\title{
Syndecan-1 is a novel molecular marker for triple negative inflammatory breast cancer and modulates the cancer stem cell phenotype via the IL-6/STAT3, Notch and EGFR signaling pathways
}

Sherif Abdelaziz Ibrahim ${ }^{1 *}$, Ramy Gadalla ${ }^{1}$, Eslam A. El-Ghonaimy ${ }^{1}$, Omnia Samir ${ }^{1}$, Hossam Taha Mohamed ${ }^{1}$, Hebatallah Hassan ${ }^{1}$, Burkhard Greve ${ }^{2}$, Mohamed El-Shinawi ${ }^{3}$, Mona Mostafa Mohamed ${ }^{1}$ and Martin Götte ${ }^{4^{*}}$

\begin{abstract}
Background: Inflammatory breast cancer (IBC), a particularly aggressive form of breast cancer, is characterized by cancer stem cell (CSC) phenotype. Due to a lack of targeted therapies, the identification of molecular markers of IBC is of major importance. The heparan sulfate proteoglycan Syndecan-1 acts as a coreceptor for growth factors and chemokines, modulating inflammation, tumor progression, and cancer stemness, thus it may emerge as a molecular marker for IBC.

Methods: We characterized expression of Syndecan-1 and the CSC marker CD44, Notch-1 \& -3 and EGFR in carcinoma tissues of triple negative IBC $(n=13)$ and non-IBC $(n=17)$ patients using qPCR and immunohistochemistry. Impact of siRNA-mediated Syndecan-1 knockdown on the CSC phenotype of the human triple negative IBC cell line SUM-149 and HER-2-overexpressing non-IBC SKBR3 cells employing qPCR, flow cytometry, Western blotting, secretome profiling and Notch pharmacological inhibition experiments. Data were statistically analyzed using Student's t-test/Mann-Whitney U-test or one-way ANOVA followed by Tukey's multiple comparison tests.

Results: Our data indicate upregulation and a significant positive correlation of Syndecan-1 with CD44 protein, and Notch-1 \& -3 and EGFR mRNA in IBC vs non-IBC. ALDH1 activity and the CD44 ${ }^{(+)} \mathrm{CD} 24^{(- \text {low })}$ subset as readout of a CSC phenotype were reduced upon Syndecan-1 knockdown. Functionally, Syndecan-1 silencing significantly reduced 3D spheroid and colony formation. Intriguingly, qPCR results indicate downregulation of the IL-6, IL-8, CCL20, gp130 and EGFR mRNA upon Syndecan-1 suppression in both cell lines. Moreover, Syndecan-1 silencing significantly downregulated Notch-1, -3, -4 and Hey-1 in SUM-149 cells, and downregulated only Notch-3 and Gli-1 mRNA in SKBR3 cells. Secretome profiling unveiled reduced IL-6, IL-8, GRO-alpha and GRO a/b/g cytokines in conditioned media of Syndecan-1 knockdown SUM-149 cells compared to controls. The constitutively activated STAT3 and NFKB, and expression of gp130, Notch-1 \& -2, and EGFR proteins were suppressed upon Syndecan-1 ablation. Mechanistically, gamma-secretase inhibition experiments suggested that Syndecan-1 may regulate the expression of IL-6, IL-8, gp130, Hey-1, EGFR and p-Akt via Notch signaling.

(Continued on next page)
\end{abstract}

\footnotetext{
* Correspondence: isherif@sci.cu.edu.eg; martingotte@uni-muenster.de 'Department of Zoology, Faculty of Science, Cairo University, 12613 Giza, Egypt

${ }^{4}$ Department of Gynecology and Obstetrics, Münster University Hospital, Albert-Schweitzer-Campus 1, D11, 48149 Münster, Germany

Full list of author information is available at the end of the article
} 
(Continued from previous page)

Conclusions: Syndecan-1 acts as a novel tissue biomarker and a modulator of CSC phenotype of triple negative IBC via the IL-6/STAT3, Notch and EGFR signaling pathways, thus emerging as a promising therapeutic target for IBC.

Keywords: Inflammatory breast cancer, Syndecan-1, Proteoglycan, Cancer stem cell, IL-6/STAT3, Notch, EGFR

\section{Background}

Inflammatory breast cancer (IBC), the most aggressive form of breast cancer, represents approximately $2.5 \%$ of newly diagnosed breast cancers in the United States [1]. This percentage reaches an even higher level of $5-10 \%$ of breast cancer cases in North African countries such as Tunisia, Morocco, and Egypt [2, 3]. IBC is a unique disease characterized by erythema, edema of the breast, a "peau d'orange" and formation of lymphatic tumor emboli [4-6]. IBC patients have a poor survival rate with a median of 3 years compared with non-IBC [1] with no currently available targeted therapies. Based on the surrogate markers estrogen receptor or progesterone receptor (ER/PR) status and human epidermal growth factor receptor (HER)-2 expression, breast cancer can be classified into $\mathrm{ER}^{+}\left(\mathrm{ER}^{+} / \mathrm{PR}^{+}\right.$and $\left.\mathrm{HER}-2^{-}\right), \mathrm{ER}^{+} \mathrm{HER}-2^{+}$ $\left(\mathrm{ER}^{+} / \mathrm{PR}^{+}\right.$and HER-2 $\left.{ }^{+}\right), \mathrm{HER}-2^{+}\left(\mathrm{ER}^{-} / \mathrm{PR}^{-}\right.$and HER-2 $\left.{ }^{+}\right)$, and triple negative $\left(\mathrm{ER}^{-} / \mathrm{PR}^{-}\right.$and HER-2 $\left.{ }^{-}\right)$[7, 8]. IBC possess the same molecular subtypes as non-IBC $[9,10]$, with more than $50 \%$ being reported as $\mathrm{ER}^{-}, 36-60 \%$ HER- $2^{+}$, and $30 \%$ triple negative according to a multinational IBC registry $[1,4]$. Therefore, the percentage of triple negative breast cancer is higher for IBC compared to non-IBC cases $[7,11,12]$. Several lines of evidence indicate that the aggressive phenotype of IBC is due to enrichment for chemo- and radioresistant cancer stem cells (CSCs) [13]. These cells are characterized by selfrenewal, unlimited and high proliferative potential, expression of multidrug-resistance proteins, efficient DNA repair capacity and apoptosis resistance $[14,15]$. Using flow cytometry, CSCs can be distinguished from the bulk of the tumor by their expression of cell surface makers CD44 and $\mathrm{CD} 24$ (as a CD44 $4^{(+)} \mathrm{CD} 24^{(- \text {llow })}$ subpopulation) and based on the activity of ALDH1 [16]. Due to their functional link to therapeutic resistance, CSCs represent an attractive therapeutic target to dampen tumor recurrence $[15,16]$.

Syndecan-1 (CD138), a cell surface heparan sulfate proteoglycan, emerges as a candidate target for IBC. It acts as a coreceptor for a multitude of biological factors like growth factors, angiogenic factors, cytokines and chemokines [17-21]. Dysregulated expression and a potential role of Syndecan-1 as a modulator of cell proliferation and invasive growth have been demonstrated in different tumor entities including breast cancer [22-26]. The function and (de)differentiation state of CSCs are substantially modulated by many interconnected signaling pathways e.g. IL-6/STAT3, Hedgehog, WNT and Notch signaling that emerge as relevant therapeutic targets [27, 28]. Interestingly, we and others uncovered the regulatory role played by Syndecan-1 in IL-6/STAT3 and WNT signaling in the human triple negative (MDA-MB-231) and hormone-receptor positive (MCF-7) non-IBC cell lines [16], and in Syndecan-1- knockout mice [29, 30]. While these data suggest that a therapeutic targeting of Syndecan-1 may be a mean of synchronously interfering with multiple relevant pathogenetic routes, the precise role of Syndecan-1 in modulating IBC pathogenesis and its CSC phenotype is still unexplored.

The cell surface epidermal growth factor receptor (EGFR) is overexpressed in approximately 50\% of triple negative IBC [31]. Patients with EGFR-positive tumors are characterized by lower survival rates and are associated with the risk of higher tumor recurrence [32, 33]. EGFR and/or HER-2 overexpression, and MAPK hyperactivation lead to activation of $\mathrm{NFKB}$ associated with ER downregulation in IBC specimens [34]. Moreover, a significantly positive correlation between EGFR and CD44 expressions exists in breast invasive ductal carcinoma patients and that is associated with the worst prognosis [35]. Interestingly, in a study of 230 surgical specimens of primary colorectal carcinoma, epithelial positive Syndecan-1 immunostaining was significantly associated with tumor size and EGFR expression [36].

In this study, we examined the expression of Syndecan-1 and its correlation with the CSC marker CD44, Notch-1 \& -3 and EGFR expression in carcinoma tissues of triple negative IBC and non-IBC patients. We further employed siRNA-mediated Syndecan-1 knockdown in the human IBC cell line SUM-149 and HER-2 overexpressing non-IBC SKBR3 cells to decipher its impact on a CSC phenotype $\left(\mathrm{CD} 44^{(+)} \mathrm{CD} 24^{(-/ \text {low })}\right.$ and $\mathrm{ALDH}^{+}$subpopulations). Of particular importance,, we studied the expression and activity of several distinct signaling pathways relevant for CSC function to address possible underlying molecular mechanism(s) for this effect. Supported by an unbiased cytokine array screening approach, we specifically tested the effect of Syndecan-1 depletion on inflammatory signaling, including the IL-6/ STAT3 signaling pathway [37-39]. Furthermore, we investigated a potential impact on the stemness-associated Notch and EGFR pathways [35, 39]. Our data demonstrate that Syndecan-1 expression is higher in tissues of triple negative IBC than that in non-IBC. Further, 
Syndecan-1 is a modulator of the CSC phenotype of IBC via IL-6/STAT-3, Notch and EGFR signaling. Therefore, Syndecan-1 may act as a novel marker for this disease and its targeting could have therapeutic implications for IBC patients.

\section{Methods}

\section{Antibodies and reagents}

The antibodies against p-STAT3 ${ }^{(\mathrm{Y} 705)}$, STAT-3, p-NFkBp65 ${ }^{\text {(Ser276) }}$, NFkB-p65, p-Akt ${ }^{\text {(Ser473) }}$, Akt and CD44 (clone 156-3-c11) were from Cell Signaling Technology, Inc. (Beverly, MA, USA), gp130 antibody was purchased from R\&D Systems (Minneapolis, MN, USA). Antihuman Notch-1 and EGFR antibodies were from Santa Cruz Biotechnology (Santa Cruz, CA, USA), antihuman-CD44-FITC, anti-human-CD24-PE, IgG2b-FITC, IgG1-PE antibodies and rhEGF were obtained from Immunotools (Friesoythe, Germany), and anti-Syndecan-1 (clone B-A38) was from Biorad (Hercules, CA, USA). Anti-human-Notch-2-PE \& APC, Syndecan-1 (CD138)$\mathrm{PE}$ antibodies were from eBioscience, Inc. (San Diego, CA, USA) and HRP-conjugated secondary antibodies were from KPL (Gaitherburg, MD, USA). Gamma-secretase inhibitor (GSI) was from Calbiochem (Darmstadt, Germany). Media, fetal calf serum (FCS) and tissue culture supplies were from Lonza (Basel, Switzerland). Unless otherwise stated, all chemicals were from Sigma (St. Louis, MO, USA).

\section{Cell culture}

The human IBC cell line SUM-149 (a kind gift from Dr. Bonnie Sloane, Wayne State University, Detroit, MI, USA) and the non-IBC cell line SKBR3 (ATCC/LGC Promochem, Wesel, Germany) were maintained in HAM's-F12 and DMEM containing 10\% FCS, 1\% glutamine and $1 \%$ penicillin/streptomycin in a humidified atmosphere of $5 \% \mathrm{CO}_{2}$ at $37{ }^{\circ} \mathrm{C}$, respectively.

\section{Patient's samples}

We enrolled 30 triple negative breast cancer patients from the breast clinic of Ain Shams university hospitals (IBC $n=13$, non-IBC $n=17$ ). Carcinoma tissues were divided into two parts: one part was fixed in 10\% neutral formalin buffered for immunohistochemical staining and the other part was frozen in $-80^{\circ} \mathrm{C}$ for subsequent isolation of total RNA.

\section{Immunohistochemical staining of CD44 and Syndecan-1}

Immunohistochemical staining was performed on serial formalin-fixed and paraffin- embedded tissues sectioned at $4 \mu \mathrm{m}$-thickness as we previously described [40]. Tissue sections were deparaffinized by two consecutive incubations in xylene for $10 \mathrm{~min}$ each, followed by rehydration through two changes of absolute ethanol, graded decreasing concentrations of ethanol for $5 \mathrm{~min}$ each and finally in distilled water. For antigen retrieval, slides were incubated in citrate buffer $(\mathrm{pH}=6.0)$ in a water steamer for $30 \mathrm{~min}$. Slides were left to cool at room temperature for $20 \mathrm{~min}$ then washed $3 \times 5$ min with PBS. Endogenous peroxidase activity of the tissue was blocked with 3\% hydrogen peroxide for $5 \mathrm{~min}$ (Dual Endogenous Enzyme block, Dako K4065, Glostrup, Denmark) and slides were washed with PBS $3 \times 5 \mathrm{~min}$. Tissue sections were blocked in $1 \%$ BSA/PBS and incubated overnight at $4{ }^{\circ} \mathrm{C}$ in a humidified chamber with the primary anti-CD44 (dilution 1:800) and antiSyndecan-1 antibodies (dilution 1:100). Afterwards, slides were washed $3 \times 5 \mathrm{~min}$ and incubated with HRP-Rabbit/Mouse (DAKO EnVision + Dual Link System-HRP $(\mathrm{DAB}+)$ for $30 \mathrm{~min}$ at room temperature. Then, nuclei were counterstained with hematoxylin, sections were mounted with Permount ${ }^{\circ}$ and imaged. Negative control slides were run in parallel where primary antibodies were omitted.

\section{siRNA-mediated knockdown of Syndecan-1 expression}

siRNA knockdown was performed using a negative control siRNA (negative control \#1, Ambion, Cambridgeshire, UK) and siRNA \#12634 (Ambion) to target Syndecan-1 coding region. Cancer cell lines were transfected with 20 nM siRNA using Dharmafect reagent (Dharmacon, Lafayette, CO, USA) according to the manufacturer's instructions. Successful knockdown was confirmed by flow cytometry as previously described [16, 22].

\section{Flow cytometry}

To detect cell surface breast CSC markers, control and Syndecan-1 siRNA transfected cells were incubated with $10 \mu \mathrm{l}$ of anti-CD44-FITC, anti-CD24-PE and the FITC and $\mathrm{PE}$ isotype control antibodies for $30 \mathrm{~min}$ at room temperature in the dark. Analogously, cells were analyzed for Syndecan-1 (CD138)-PE in combination with Notch-2-PE or-APC antibodies. Stained cells were analyzed by a cube- 8 flow cytometer (Sysmex/Partec, Muenster, Germany). For ALDH1 activity assessment, $1 \times 10^{6}$ control and Syndecan-1 siRNA transfected cells were resuspended in assay buffer containing ALDH1 substrate $(1 \mu \mathrm{mol} / \mathrm{L})$. Half of this suspension was incubated with $50 \mathrm{mM}$ ALDH1 inhibitor diethylaminobenzaldehyde (DEAB) as negative control. Afterwards, the cells were incubated for $1 \mathrm{~h}$ at $37{ }^{\circ} \mathrm{C}$ in water bath in dark with agitation at 10 min interval. Finally, the cells were centrifuged at $400 \mathrm{xg}$ for $5 \mathrm{~min}$ and were resuspended in $1 \mathrm{~mL}$ assay buffer and stored on ice prior to acquisition by flow cytometry. 


\section{Quantitative real-time PCR}

Total RNA isolated from cultured cells or frozen tissues using GeneJET RNA Purification Kit (Thermoscientific, Waltham, USA) was reverse transcribed into cDNA using the high capacity cDNA Kit (Applied Biosystems, Foster City, CA, USA). Quantitative real-time PCR was conducted in duplicate for each gene of interest using SYBR Green dye and gene expression levels were measured in a steponeplus detection System (Applied Biosystems). Relative gene expression was evaluated using the $2^{-\Delta \Delta} \mathrm{Ct}$ method after normalization to $18 \mathrm{~S}$ rRNA or GAPDH as previously described [22]. Melting curve analysis was performed to confirm specific product amplification. Primers were designed using Primer 3.0 software or referred to the published literature. Primer sequences are listed in Additional file 1: Table S1. For Notch pharmacological inhibition experiments, $1 \mu \mathrm{M}$ GSI was added for control and Syndecan-1 siRNA transfected SUM-149 cells 24 h before RNA extraction. Data for mRNA expression levels in carcinoma tissues of IBC vs non-IBC (normalized to values of normal tissues collected during reduction mammoplasty) was represented as log2-transformed fold change.

\section{Sodium dodecyl sulfate-polyacrylamide gel electrophoresis (SDS-PAGE) and immunoblotting}

Briefly, $72 \mathrm{~h}$ post transfection, control and Syndecan-1 siRNA transfected cells were washed twice with PBS and lysed in RIPA buffer containing protease and phosphatase inhibitors [22]. The cell lysates were shaked for $20 \mathrm{~min}$ followed by centrifugation at $10,000 \mathrm{xg}$ for $10 \mathrm{~min}$ at $4{ }^{\circ} \mathrm{C}$. Supernatant was collected and protein concentration was determined using Bradford assay (Fermentas, Burlington, ON, Canada). 25-50 $\mu \mathrm{g}$ of protein per lane was separated on $10-12 \%$ gels and electrotransferred into polyvinylidene fluoride (PVDF) membrane (Millipore, USA). Immunoblotting was performed using primary antibodies against phospho-NFkB/ p65 ${ }^{\text {(Ser276) }}$, phospho-STAT3 ${ }^{(\mathrm{Y} 705)}$, phospho-Akt ${ }^{(\text {Ser473), }}$, Akt, gp130, Notch-1, EGFR and HRP-conjugated secondary antibodies. After washing, specifically bound antibodies were visualized by ECL reaction. Visualized bands were analyzed with ImageJ software (National Institutes of Health, Bethesda, MA, USA) using $\beta$-actin or tubulin as loading controls.

\section{Three dimensional (3D) spheroids and colony formation assays}

Petri-dishes were coated with $150 \mu \mathrm{l}$ Cultrex ${ }^{\circ}$ Basement Membrane Extract (BME) (Trevigen, Inc., MD, USA) and incubated at $37{ }^{\circ} \mathrm{C}$ in a $\mathrm{CO}_{2}$ incubator for $15 \mathrm{~min}$ to solidify. Control and Syndecan-1 siRNA transfected SUM-149 and SKBR3 cells were mixed with 2\% BME at density of $5 \times 10^{4}$ before overlaying onto each coated petridish and incubated for 7-10 days at $37{ }^{\circ} \mathrm{C}$ to allow spheroid formation in 3D. The media were changed every 3-4 days, the spheroids were stained with cell tracker red dye, and the number of spheroids $(>50 \mu \mathrm{m})$ was counted. To examine the effect of Syndecan-1 silencing on clonogenic ability, 10,000 control and Syndecan1 knockdown SUM-149 cells were seeded in six-well plates and maintained in Ham-F12 with $10 \%$ FBS for 10-14 days as previously performed [41]. Cells were washed with PBS, fixed in methanol for $20 \mathrm{~min}$ and stained with $0.05 \%$ crystal violet for $15 \mathrm{~min}$. Excess stain was removed by water and the stain was dissolved in $1 \mathrm{ml} \mathrm{10 \%} \mathrm{glacial} \mathrm{acetic} \mathrm{acid.} \mathrm{The} \mathrm{released} \mathrm{color} \mathrm{was}$ measured by spectrophotometry at $595 \mathrm{~nm}$ according to [42]. Colony formation steps were also performed in presence of $10 \mathrm{ng} / \mathrm{mL}$ EGF and 1\% FBS (with addition of fresh media at interval 3-4 days) or $1 \mu \mathrm{M}$ GSI for $24 \mathrm{~h}$ followed by exchange with complete growth media.

\section{Secretome profiling of conditioned media of SUM-149 cells grown in 3D spheroids}

Cytokines, chemokines and growth factors secreted by control and Syndecan-1-silenced SUM-149 cells grown in $3 \mathrm{D}$ were detected in conditioned media $(\mathrm{CM})$ using RayBio cytokine array-C3 (RayBiotech, Inc. GA, USA). All steps needed to form 3D spheroids were analogously performed followed by starvation for $24 \mathrm{~h}$. Media conditioned by the secretome of the cells were collected and subjected to profile 42 biological factors according to the manufacturer's instructions. The signal intensity of each spot, which represents the secreted chemokine, cytokines, and growth factors was evaluated by subtracting from the background and normalized to positive controls using ImageJ software as we previously described [40].

\section{Statistical analysis}

All Data are presented as mean \pm SEM or SD as indicated. Differences among variables were evaluated using $x^{2}$, or Fischer's exact tests. Student's t-test (for normally distributed data) or Mann-Whitney U-test (for nonnormally distributed data) was used for two group comparisons. The statistical difference between more than two groups was evaluated by one-way ANOVA followed by Tukey's multiple comparison test. The Pearson's Rank correlation test was used to analyze the correlations. The level of significance was set at $p<0.05$. Graphs were plotted and analyses were performed by GraphPad Prism 7 software (San Diego, CA, USA) and IBM SPSS version 22 (Chicago, IL, USA).

\section{Results}

Clinical and pathological characteristics of patients

The clinical and pathological characteristics of patients included in this study are represented in Table 1 . There 
Table 1 Clinical and pathological data of IBC and non-IBC patients

\begin{tabular}{|c|c|c|c|}
\hline Characteristic & $\mathrm{IBC}(N=13)$ & Non-IBC $(N=17)$ & $P$ value \\
\hline \multicolumn{4}{|l|}{ Age } \\
\hline Range & $29-60$ & $35-63$ & \multirow[t]{3}{*}{$0.119^{a}$} \\
\hline Mean \pm SD & $45.15 \pm 8.98$ & $50.11 \pm 9.43$ & \\
\hline NA & 0 & 0 & \\
\hline \multicolumn{4}{|l|}{ Tumor size } \\
\hline$\leq 4$ & $2(16.7 \%)$ & $2(11.8 \%)$ & \multirow[t]{3}{*}{$1.000^{\mathrm{b}}$} \\
\hline$>4$ & 10 (83.3\%) & $15(88.2 \%)$ & \\
\hline NA & 1 & 0 & \\
\hline \multicolumn{4}{|c|}{ Lymph node status } \\
\hline$<4$ & $1(10 \%)$ & $7(41.2 \%)$ & \multirow[t]{3}{*}{$0.098^{b}$} \\
\hline$\geq 4$ & $9(90 \%)$ & $10(58.8 \%)$ & \\
\hline NA & 3 & 0 & \\
\hline \multicolumn{4}{|l|}{ Tumor grade } \\
\hline G1 & 0 & 0 & \multirow[t]{5}{*}{$0.332^{b}$} \\
\hline G2 & $7(58.3 \%)$ & $14(82.4 \%)$ & \\
\hline G3 & $4(33.3 \%)$ & $3(17.6 \%)$ & \\
\hline G4 & $1(8.3 \%)$ & 0 & \\
\hline NA & 1 & 0 & \\
\hline \multicolumn{4}{|c|}{ Lymphovascular invasion } \\
\hline Negative & $3(27.3 \%)$ & $13(76.5 \%)$ & \multirow[t]{3}{*}{$0.018^{* \mathrm{~b}}$} \\
\hline Positive & $8(72.7 \%)$ & $4(23.5 \%)$ & \\
\hline NA & 2 & 0 & \\
\hline
\end{tabular}

Data are expressed as mean $\pm \mathrm{SD}$

$N A$ Data not available

${ }^{*}$ significant $P$ value calculated by ${ }^{\text {a }}$ Student's t-test or ${ }^{\text {b }}$ Fisher's exact test

were 13 IBC patients with an average age of 45.15 years (range from 29 to 60 years) and 17 non-IBC patients with an average age of 50 years (range from 35 to 63 years). In the IBC group $16.7 \%$ of the patients had a tumor size $\leq 4$ and $83.3 \%$ of the patients had a tumor size $>4$, while in the non-IBC group $11.8 \%$ of the patients had a tumor size $\leq 4$ and $88.2 \%$ of the patients had a tumor size $>4$. The histological tumor grade was diagnosed as: $58.3 \%$ grade 2 (G2), $33.3 \%$ grade 3 (G3) and $8.3 \%$ was Grade 4 (G4) in IBC and was diagnosed as: $82.4 \%$ grade 2 (G2) and $17.6 \%$ grade 3 (G3) in non-IBC. The lymph nodes metastasis status was subdivided according to the number of positive metastatic lymph nodes into $<4$ and $\geq 4$. All IBC patients who underwent surgery were lymph nodes metastasis positive: $10 \%$ had $<4$ positive lymph nodes and $90 \%$ had $\geq 4$ positive metastatic lymph nodes. In non-IBC patients, $41.2 \%$ had $<4$ lymph nodes involvement and $58.8 \%$ had $\geq 4$ positive lymph nodes. Therefore, there is a trend toward women with IBC showing increased incidence of $\geq 4$ positive metastatic lymph nodes compared with non-IBC women $(P=0.098)$. Pathological examination of IBC and nonIBC tissue sections revealed that lymphovascular invasion is positive in $72.7 \%$ and $23.5 \%$ in IBC and nonIBC, respectively. The presence of lymphovascular invasion in carcinoma tissues of IBC was significantly higher $(P=0.018)$ than that in non-IBC.

\section{Higher expression with a positive correlation of Syndecan-1 with CD44 in carcinoma tissues of triple- negative IBC vs non-IBC patients}

Although Syndecan-1 expression is a prognostic marker for different tumor entities including breast cancer, and is a modulator of breast and prostate CSCs $[16,43]$, its role in IBC pathogenesis is still unknown. Therefore, we analyzed Syndecan-1 expression by $\mathrm{qPCR}$ or immunohistochemical staining in carcinoma tissues of triple negative IBC vs non-IBC patients. Relative to non-IBC, our data indicate a significantly higher expression of Syndecan-1 transcript levels $(P<0.01)$ (Fig. 1a), and higher positive staining of Syndecan-1 protein in tissues of IBC $(P<$ 0.01 ) (Fig. 1b), and on carcinoma cells infiltrated into lymphatic vessels, a unique feature for IBC (Additional file 2: Figure S1).

IBC is essentially characterized by chemo- and radioresistance, which may be attributed to the existence of CSCs $[13,44]$. Therefore, we next investigated expression of the CSC marker CD44 in triple negative IBC vs non-IBC. Our data showed that tissues of triple negative IBC exhibited a significantly higher CD44 staining than those of non-IBC patients $(P<0.05)($ Fig. 1b). This finding suggests that IBC tissues may display higher CSC properties than those of non-IBC patients. Interestingly, a significant positive correlation was found between expression of Syndecan-1 and CD44 in IBC $(r=0.87$, $P<0.001)$ and in non-IBC $(r=0.54, P<0.05)$ (Fig. 1c), suggesting a functional association and an essential role in IBC patients.

We next investigated expression and distribution of Syndecan-1 and the CSC marker CD44 in our experimental models; the human triple negative IBC SUM149 cell line and the HER-2 overexpressing non-IBC SKBR3 cell line. Our findings indicate that the CD $44^{(+)}$Syndecan- ${ }^{(+)}$subset represents approximately $62.12 \%$ and $1.07 \%$ in SUM-149 and SKBR3 cells, respectively. The CD $44^{(+)}$Syndecan- $1^{(-)}$subset represents $32.31 \%$ and $2.01 \%$, and the CD $44^{(-)}$Syndecan- ${ }^{(+)}$subset represents $0.98 \%$ and $26.57 \%$ in SUM-149 and SKBR-3 cells, respectively (Fig. 1d\&e ). This means that the $\mathrm{CD} 44^{(+)}$-enriched Syndecan-1 subset constitutes $98.5 \%$ and $3.9 \%$ of total Syndecan-1 expression in SUM-149 and SKBR3 cells, respectively. This conforms to our findings in the clinical tissue specimens and proves that Syndecan-1 is coexpressed and may possess a functional link to the CSC marker CD44 in triple negative IBC. 

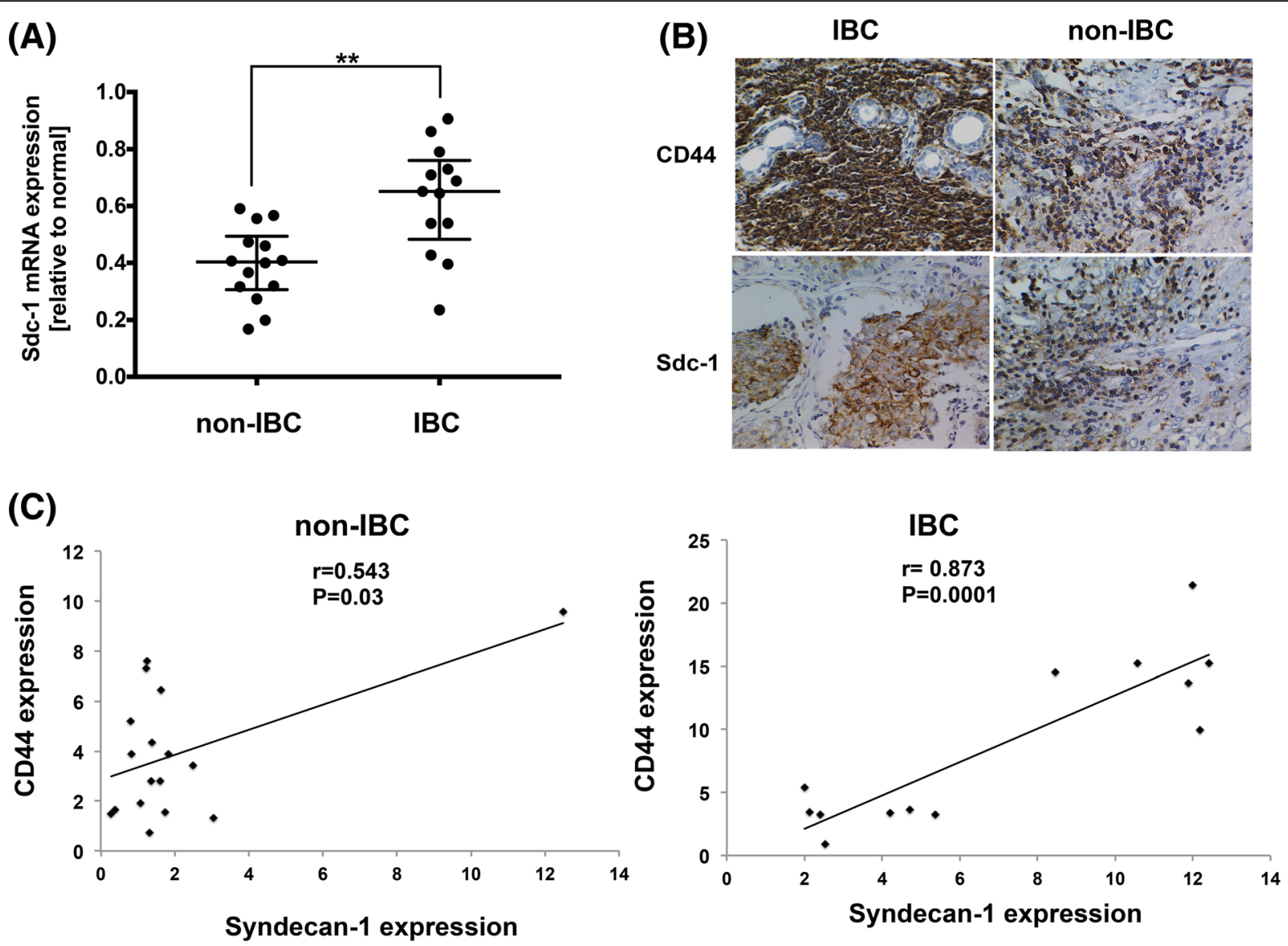

(D)
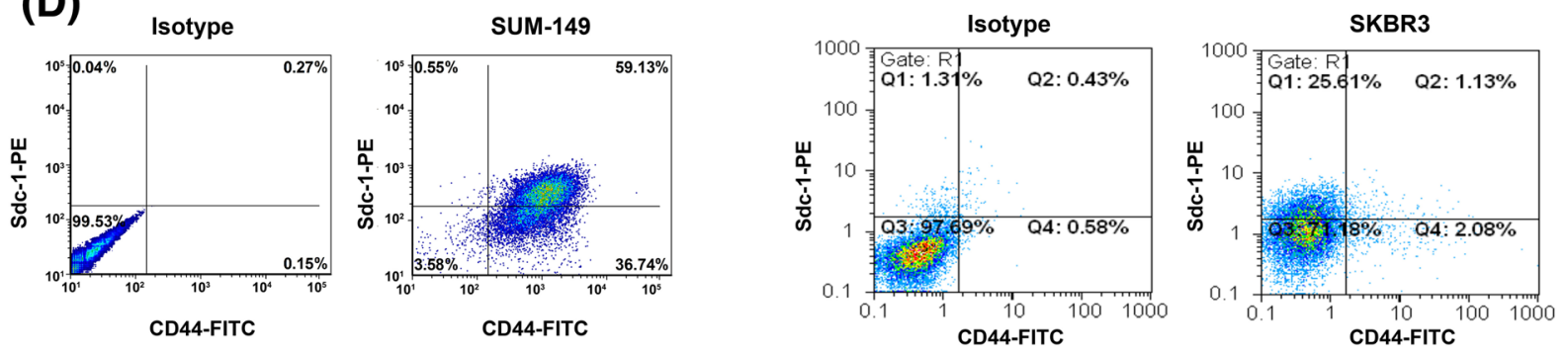

(E)

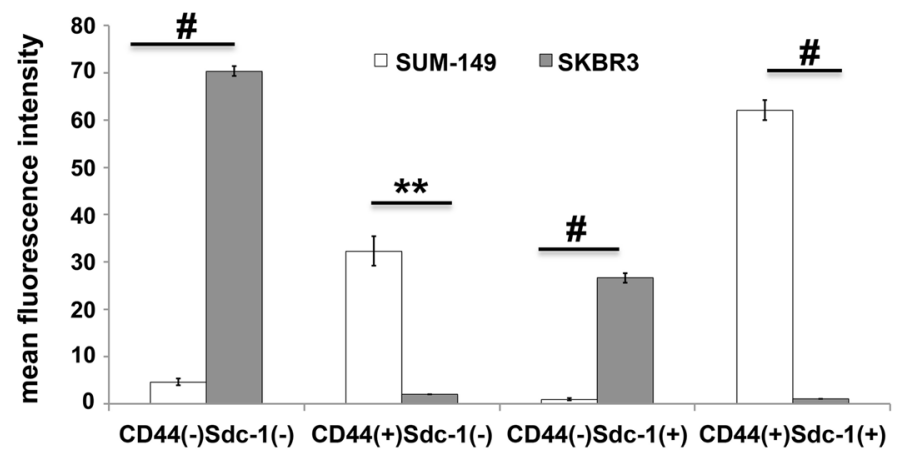

Fig. 1 (See legend on next page.) 
(See figure on previous page.)

Fig. 1 Expression of Syndecan-1 and the CSC marker CD44 in carcinoma tissues of IBC vs non-IBC patients, SUM-149 and SKBR3 cells. a Higher expression of Syndecan-1 mRNA level in carcinoma tissues of IBC $(n=13)$ vs non-IBC $(n=14)$. RQ values of mRNA expression are log2-transformed and normalized to values of normal tissues collected during reduction mammoplasty. Bars represent median with interquartile range. ${ }^{* *} P<0.01$ as determined by Mann-Whitney U-test. b Representative fields of immunostaining (brown color) of Syndecan-1 and CD44 in paraffin embedded carcinoma tissue sections of triple negative IBC $(n=13)$ and non-IBC $(n=17)$ patients. A high density of cancer cells positive for CD44 and Syndecan-1 is observed in IBC vs non-IBC. c Pearson's correlation between Syndecan-1 and CD44 expression in carcinoma tissues of IBC vs non-IBC. d A representative flow cytometric analysis for the expression of CD44 and Syndecan-1 in SUM-149 and SKBR3 cells. e Quantitative analysis of four subpopulations; CD44 $4^{(-)}$Syndecan-1 ${ }^{(-)}, \mathrm{CD}_{4} 4^{(+)}$Syndecan-1 $1^{(-)}, \mathrm{CD} 44^{(-)}$Syndecan- $1^{(+)}$and CD44 $4^{(+)}$Syndecan-1 ${ }^{(+)}$. Syndecan-1 is higher expressed in the CD44 ${ }^{(+)}$-enriched subset in SUM-149 cells than that in SKBR3 cells. Data represent mean \pm SEM, $n \geq 3 .{ }^{* *} P<0.01, \# P<0.001$ as determined by Student's t-test. Data shown are a single experiment representative of three independent experiments

\section{Syndecan-1 silencing significantly reduces the CD44 ${ }^{(+)}$CD2 $4^{(-/ \text {low })}$ pool and ALDH1 activity in SUM-149 and SKBR3 cells}

We have previously shown that Syndecan-1 is a modulator of breast cancer stemness in MDA-MB-231 and MCF-7 cells [16]. To formally test if Syndecan-1 is also of relevance for CSCs of SUM-149 and SKBR3 cells, we analyzed the effect of Syndecan-1 knockdown on CSC properties, namely the $\mathrm{CD} 44^{(+)} \mathrm{CD} 24^{(-/ \text {low })}$ subpopulation and ALDH1 activity. Successful downregulation of Syndecan-1 in both cell lines was confirmed by flow cytometry (Additional file 3: Figure S2). We next analyzed the expression of CD44 and CD24 in control and Syndecan-1-silenced SUM-149 cells by flow cytometry. siRNA-mediated Syndecan-1 depletion significantly reduced the $\mathrm{CD} 44^{(+)} \mathrm{CD} 24^{(-/ \text {low })}$ pool by $19.5 \%$ as compared with control cells (with an average of $66.2 \% \pm 2.1 \%$ in control cells and $53.1 \% \pm 1 \%$ in Syndecan-1 siRNA transfected cells) $(P<0.01, n=4)$ (Fig. 2a). Although the $\mathrm{CD} 44^{(+)} \mathrm{CD} 24^{(+)}$subset increased upon Syndecan-1 depletion, it did not reach the significance level (Fig. 2a).

We further characterized the activity of ALDH isoform 1 (ALDH1), an additional surrogate marker for CSCs [14] using Aldefluor assay. Flow cytometric analysis of ALDH1 activity uncovered that siRNA-mediated Syndecan-1 depletion diminished the ALDH1-positive subpopulation by $22 \%$ in SUM-149 cells (with an average of $24.6 \% \pm 1.9 \%$ in control cells and $17.3 \% \pm 1.1 \%$ in Syndecan-1siRNA cells, $P<0.05$ ) (Fig. $2 \mathrm{~b}$ ) and by $42 \%$ in SKBR-3 cells (with an average of $18.9 \% \pm 0.6 \%$ in control cells and $11.9 \% \pm 1.8 \%$ in Syndecan-1 siRNA transfected cells, $P<0.01$ ) (Fig. 2c) compared with control cells. Taken together, these findings further validate the key role played by Syndecan-1 in regulating the stem cell phenotype in different molecular subtypes of IBC and non-IBC cell lines.

\section{Syndecan-1 knockdown perturbs the formation of colonies and spheroids growing in 3D}

Since colony and spheroids formation are unique properties for tumorigenesis and self-renewal of CSCs [16], we evaluated the influence of Syndecan-1 on this process in breast cancer cell lines in vitro. Single cell suspensions of control and Syndecan-1 siRNA transfected SUM-149 and SKBR3 cells in 2\% cultrex were overlaid on cultrex-coated Petri-dishes and cultured for 7-10 days. Our data indicate that Syndecan-1-silenced cells displayed a significantly reduced capability to form spheroids in 3D by $39 \%$ and $46 \%$ in SUM-149 and SKBR3 cells compared to control cells, respectively $(P<$ $0.01, n=3$ ) (Fig. 3a). We next examined the potential function of Syndecan-1 in regulating colony formation. Syndecan-1 ablation suppressed the colony forming capacity by $46 \%$ as compared to control SUM-149 cells $(P<$ $0.01, n=3$ ) (Fig. 3b).

\section{Syndecan-1 silencing downregulates a myriad of cancer stem cell-related genes in SUM-149 and SKBR3 cells}

CSCs are regulated by several distinct signaling pathways, including the Notch, IL-6/STAT3, and hedgehog signaling pathways [28]. Therefore, we examined whether the mRNA expression levels of components of these pathways were influenced by Syndecan-1 depletion. As depicted in Fig. $4 a \& b$, our qPCR data indicate that Syndecan-1 knockdown led to a significant downregulation of Notch-1, $-3,-4$ and the Notch signaling downstream target Hey-1 transcript levels by $45 \%$, $41 \%$, $27 \%$ and $43 \%$ in SUM-149 cells, respectively. In contrast, only a significantly reduction of Notch-3 transcript levels by $19 \%$ was evident in SKBR3 cells as compared to control cells. The activation of the Hedgehog pathway is mediated by the transcription factor Gli-1 [45]. Our data uncovered Gli-1 that transcript levels were downregulated by $31 \%$ in Syndecan-1 knockdown cells compared to control SKBR3 cells. This conforms with the observation that CD138/Syndecan- ${ }^{(+)}$multiple myeloma cells express Hedgehog genes and that inhibition of Smoothened decreased multiple myeloma cell viability by downregulating Gli-1 and Patched1 [46]. The expression of stemnessassociated inflammatory cytokines namely; IL-6 and IL-8, and gp130 mRNAs were downregulated by 39\%, 38\% and $34 \%$ in Syndecan-1-silenced SUM149 and by 55\%, 61\% and $49 \%$ in SKBR3 upon Syndecan-1 knockdown, respectively. A relevant clue for regulation of IL-6 is the chemokine CCL20, which induces proliferation of cultured 


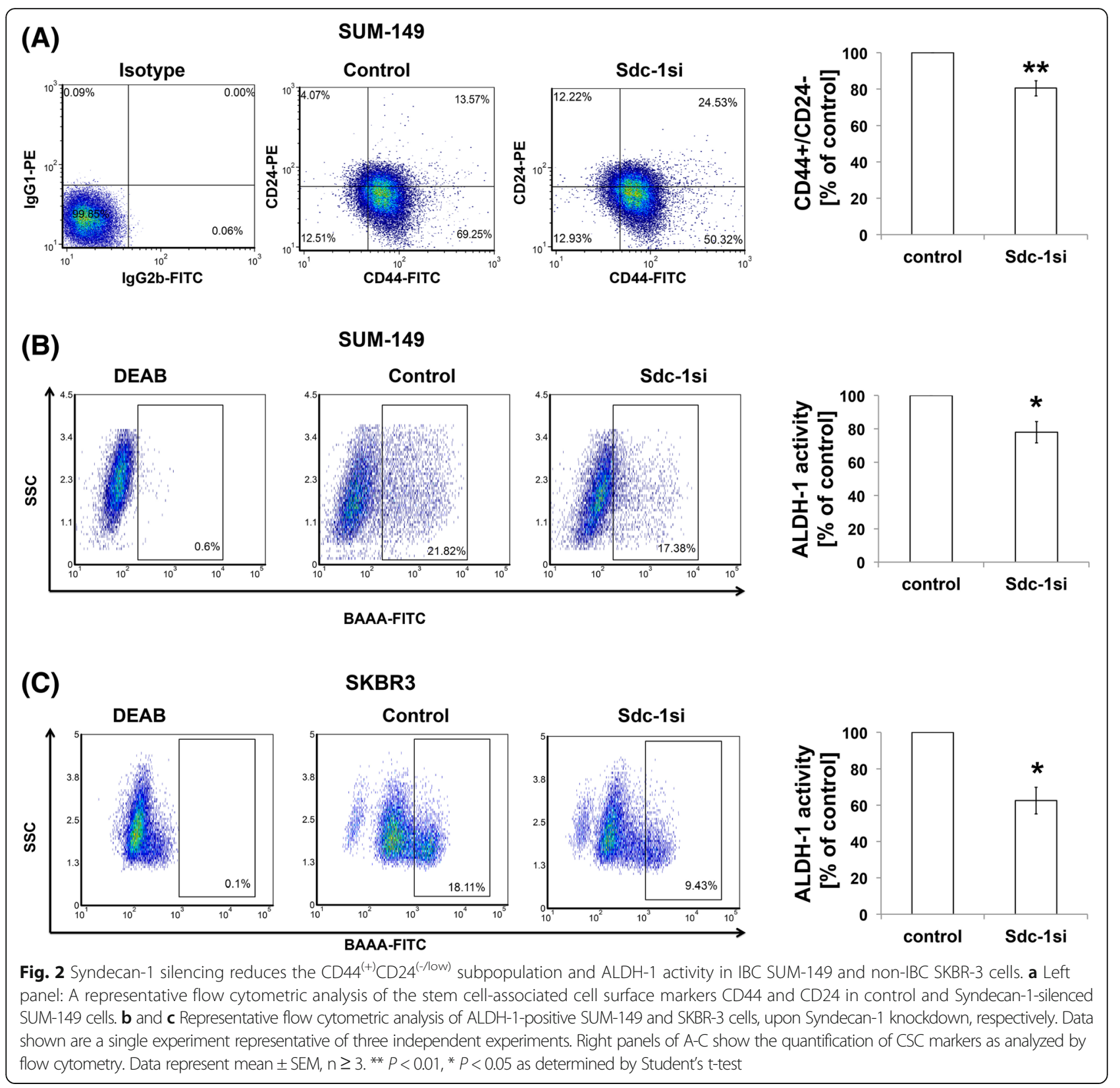

human breast epithelial cells [47] and is involved in IL-6 induction [48]. CCL20 mRNA was downregulated by $40 \%$ and 51\% in Syndecan-1 knockdown SUM-149 and SKBR3 compared to control cells, respectively, suggesting the existence of a Syndecan-1/CCL20/IL-6 axis.

\section{Syndecan-1 siRNA knockdown reduces the secretome profile of SUM-149 cells}

We further analyzed the effect of Syndecan-1 silencing on the secretome profile of SUM-149 cells. This cell line is characterized by high secretion of IL-6 and IL-8 [41], which could promote a CSC phenotype via an autocrine feedback loop. Therefore, post starvation for $24 \mathrm{~h}$, serum-free culture media collected from control and Syndecan-1-silenced SUM-149 cells were subjected to cytokine profiling. Densitometric analysis assessed by ImageJ software indicates an overall decrease in the secretions of cytokines, chemokines and growth factors by approximately $50-80 \%$ upon Syndecan-1 knockdown in SUM-149 cells (Fig. 5). Strikingly, the predominant cytokines, chemokines and growth factors secreted by SUM149 cells implicated in regulating a CSC phenotype were downregulated; namely IL-6, IL-8 and growth regulated protein GRO-alpha, and GRO a/b/g. 


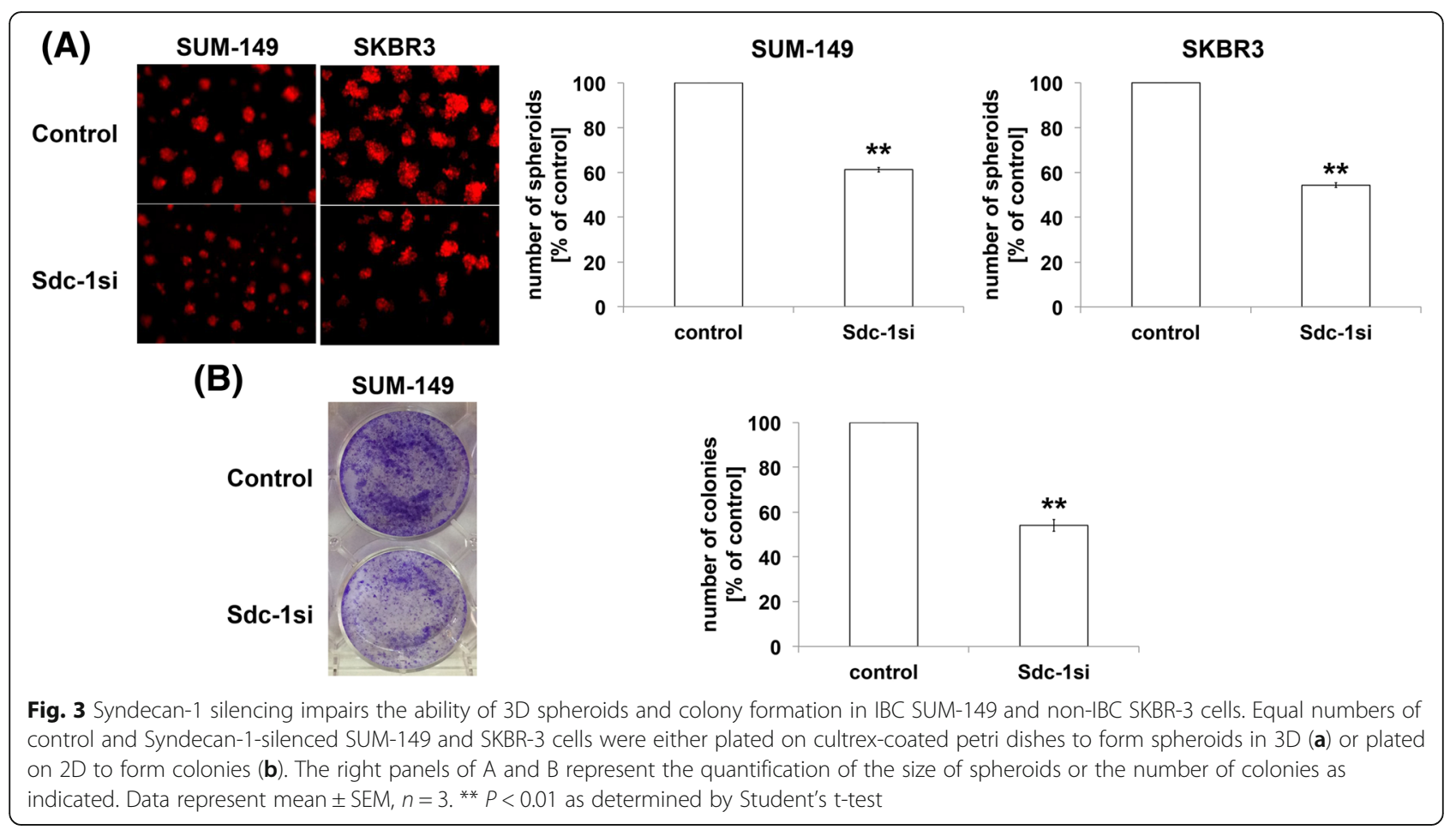

\section{Syndecan-1 silencing downregulates gp130 and} attenuates the constitutive activity of STAT3 and NFKB in SUM-149 and SKBR3 cells

We have previously shown that Syndecan-1 modulates the expression of IL-6, IL-6R in different experimental models of inflammation and in MDA-MB-231 breast cancer cells $[16,49,50]$. As IL-6 and its IL-6R/gp130 receptor complex mediate breast CSC self-renewal via STAT3 activation [27], we investigated whether Syndecan-1 depletion might affect expression of gp130

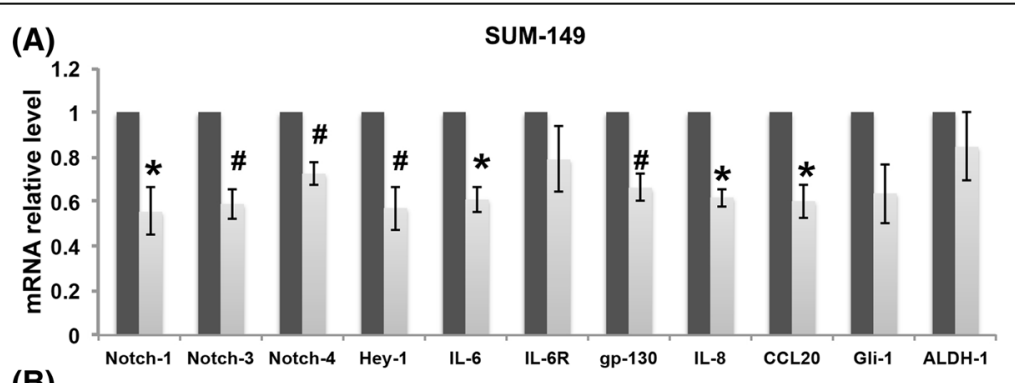

(B)

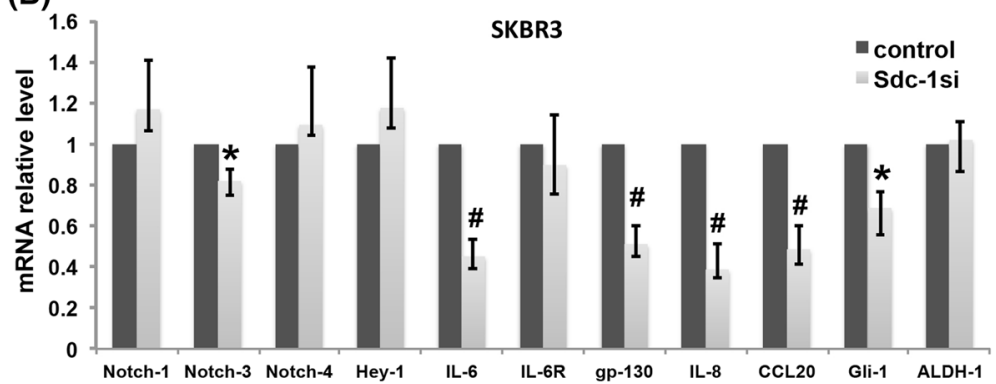

Fig. 4 Syndecan-1 silencing suppresses CSC-related gene expression in SUM-149 and SKBR3 cells. Post Syndecan-1 knockdown, total RNA isolated from SUM-149 (a) and SKBR3 cells (b) was reverse transcribed into CDNA and subjected into qPCR. Data represent mean \pm SEM, $n \geq 3$. ${ }^{*} P<0.05$, \# $P<0.01$ as determined by Student's t-test 


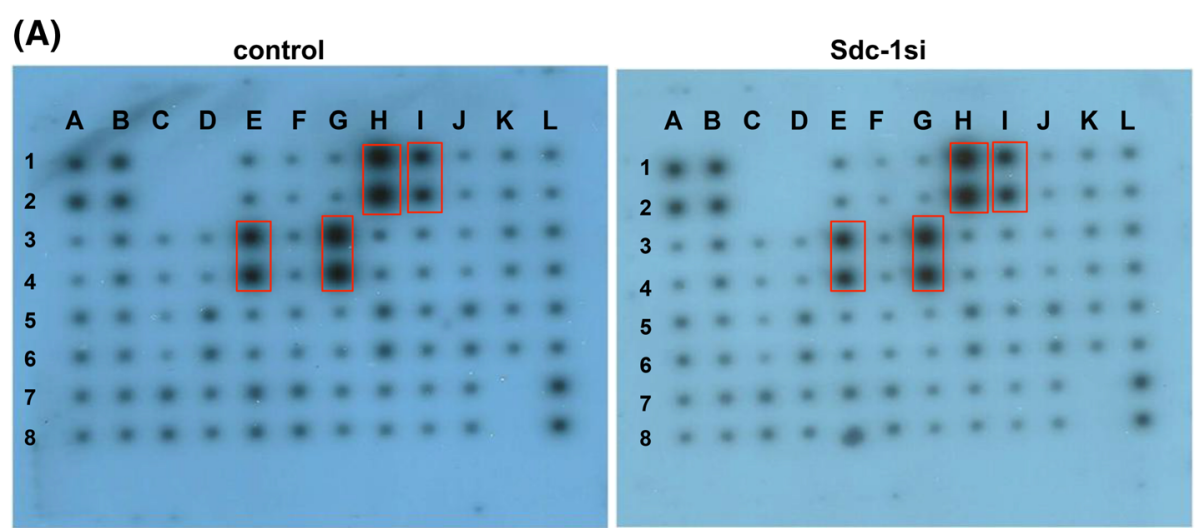

(B)

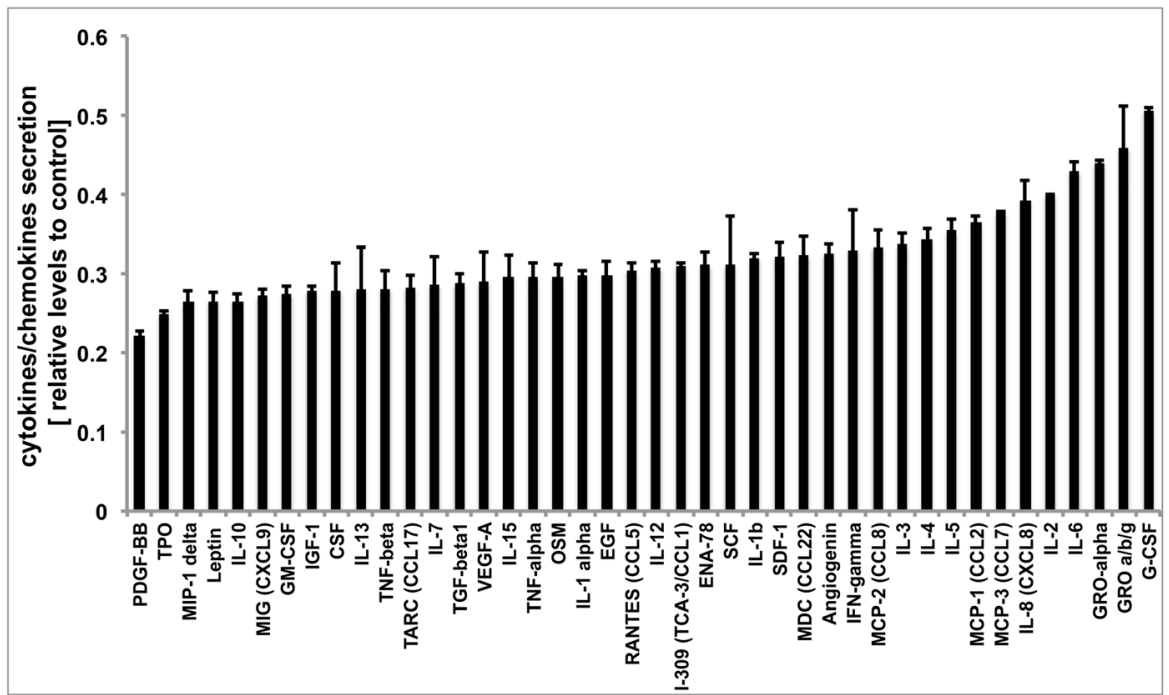

Fig. 5 Profiling of cytokines/chemokines and growth factors secreted by control and Syndecan-1 siRNA transfected SUM-149 cells. Media conditioned by secretome of control and Syndecan-1-depleted cells for $24 \mathrm{~h}$ were subjected to cytokine profiling using RayBio cytokine array-3, which detects 42 different cytokines. a A representative picture of the human cytokine protein membrane array for the secretions of control and Syndecan-1 siRNA transfectants. $\mathbf{b}$ Densitometric quantification of the signal intensity of each cytokine secreted by the cells. Control values were set to 1 . Red boxes represent the predominant secreted cytokines namely, IL-6 (E3,4), IL-8 (G3,4), GRO (H1,2) and GRO-a $(11,2)$

and the active status of STAT3 using Western blot analysis. Relative to controls, gp130 was significantly downregulated at the protein level by $43 \%$ and $24 \%$ in Syndecan-1 siRNA transfected SUM-149 and SKBR3 cells, respectively (Fig. 6a\&b). Interestingly, Syndecan-1 depletion significantly attenuated the active phosphorylated form of STAT3 by $46 \%$ and $39 \%$ in SUM-149 and SKBR3 cells, compared to control cells, respectively (Fig. 6a\&b). The transcription factor $\mathrm{NF} \kappa \mathrm{B}$ is a master regulator of a number of cytokines (e.g. IL-6 and IL-8) involved in stemness regulation in the triple negative breast cancer [51]. The level of the phosphorylated form of $\mathrm{NFkB}$ was downregulated by $46 \%$ in SUM-149 (Fig. 6a\&b). In contrast, the phosphorylated form of $\mathrm{NFKB}_{\mathrm{K}}$ was downregulated by only $12 \%$ in SKBR3 cells upon Syndecan-1 depletion compared to controls, and it did not reach the significance level $(p=0.08)$ (Fig. 6a\&b).

\section{Notch-1 and -3 are positively correlated with Syndecan-1} mRNA expression in tissues of triple negative IBC vs nonIBC

We next assessed expression of Notch-1 \& -3 transcript levels in tissues of IBC vs non-IBC. qPCR results revealed that Notch-1 was significantly upregulated in IBC in comparison with non-IBC $(P<0.01)$, whereas we couldn't detect a significant difference for expression of Notch-3 mRNA in IBC vs non-IBC (Fig. 7a). Interestingly, a significant positive correlation between Notch-1 and Syndecan-1 mRNA levels $(r=0.793, P=0.001)$ (Fig. 7b) and between Notch-3 and Syndecan-1 mRNA levels $(r=0.819, \quad P=0.001)$ 


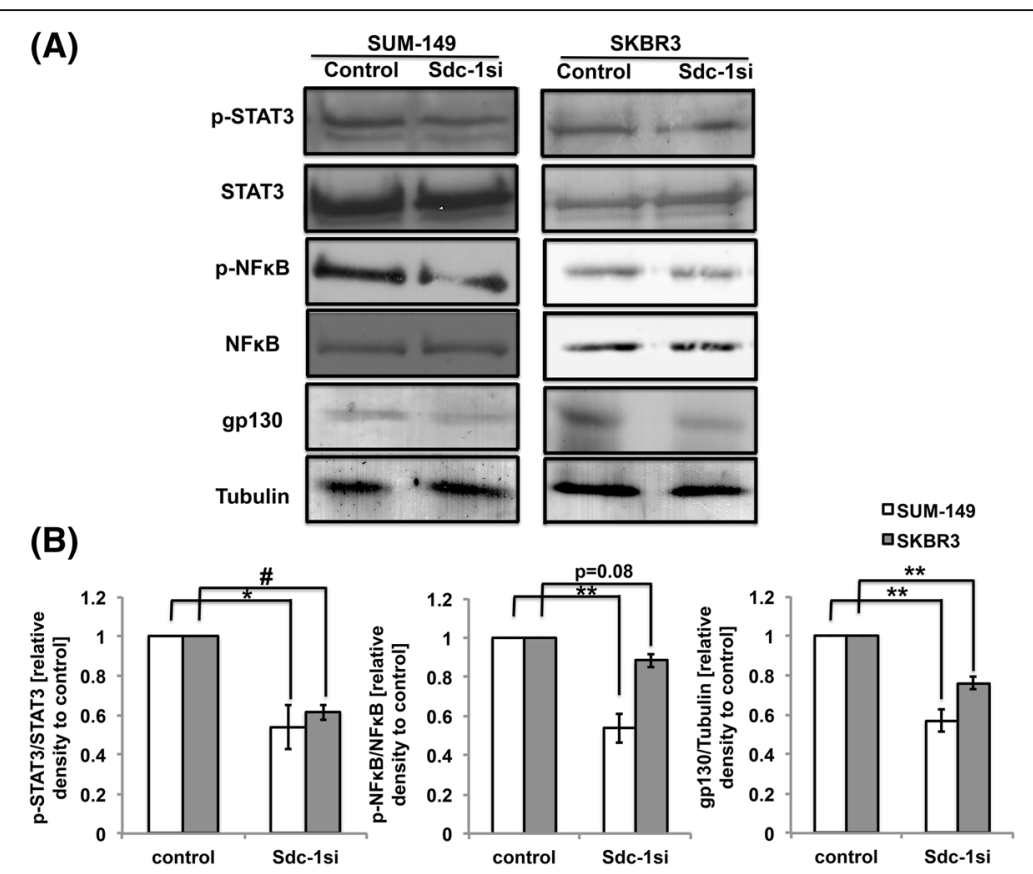

Fig. 6 Syndecan-1 silencing attenuates the activation of STAT-3 and NFKB signaling pathways and downregulates protein expression of gp130 in SUM-149 and SKBR3 cells. Seventy-two hours post transfection total cell lysates of control and Syndecan-1 knockdown cells were collected, electrophoresed and immunoblotted. The membrane was probed with the indicated antibodies. a Western blot showing expression of p-STAT-3, STAT-3, p-NFKB, NFKB and gp130 upon Syndecan-1 silencing in SUM-149 and SKBR-3 cells. $\mathbf{b}$ Immunoblot band intensities were normalized to the total form of STAT-3, NFKB or tubulin expression. Data shown are a single experiment representative of three independent experiments. ${ }^{*} P<0.05$, ** $P<0.01$ and $\# P<0.001$ as determined by Student's t-test

(Fig. 7c) did exist in carcinoma tissues of IBC. This correlation was not observed in non-IBC (Fig. 7b\&c).

Syndecan-1 orchestrates colony formation and expression of inflammatory cytokines via Notch signaling in SUM-149 cells

It has been shown that treatment of patient-derived xenograft tumors with anti-Notch-2 antibodies inhibits tumor growth and reduces the tumor-initiating cell frequency [39], suggesting the role played by Notch-2 in regulating CSC properties. Thus, we performed flow cytometric analysis for the expression and distribution of Notch-2 and Syndecan-1 in SUM-149 and SKBR3 cells. Our findings indicate that the Notch- $2^{(+)}$Syndecan- $1^{(+)}$ subset represents approximately $40.7 \%$ and $28.5 \%$ in SUM-149 and SKBR-3 cells, respectively. The Notch$2^{(+)}$Syndecan- $1^{(-)}$subset represents $28.1 \%$ and $63.1 \%$, and the Notch- $2^{(-)}$Syndecan- $1^{(+)}$subset represents $10.95 \%$ and $0.72 \%$ in SUM-149 and SKBR-3 cells, respectively (Fig. 8a\&b). This means that the Notch- $2^{(+)}$-enriched Syndecan-1 subset constitutes $78.8 \%$ and $97.5 \%$ of total Syndecan-1 expression in SUM-149 and SKBR-3 cells, respectively. These data along with our findings in clinical samples highlights a functional link of Syndecan-1 expression to Notch signaling. Therefore, we tested whether Syndecan-1 is implicated in regulation of Notch expression. Our Western blot data indicate that Syndecan-1 knockdown cells exhibited a significant reduction of Notch-1 full-length protein levels by $20 \%$ compared to control cells (Fig. 8c). Furthermore, we sought to evaluate the impact of Syndecan-1 silencing on Notch-2 expression in SUM-149 cells. Our flow cytometric analysis demonstrated a significant downregulation of Notch-2 expression by $27 \%$ in Syndecan-1silenced SUM-149 relative to control cells $(P<0.05)$ (Fig. 8c).

As we have shown that Syndecan-1 knockdown reduced expression of IL-6 and IL-8, the predominant cytokines implicated in IBC stemness regulation, we evaluated whether this effect is Notch-dependent. Therefore, control and Syndecan-1-silenced SUM-149 cells were incubated with $1 \mu \mathrm{M}$ GSI for $24 \mathrm{~h}$. qPCR results uncovered that Notch inhibition or Syndecan-1 silencing significantly downregulated expression of IL-6, gp130, IL- 8 and Hey-1 by at least $40 \%$ as compared to control cells (Fig. 8d). Of note, we did not observe any significant additive effect for Notch inhibition in Syndecan-1silenced cells, suggesting that Syndecan-1 knockdown and Notch exert their potent effect via the same downstream target. To further prove that Syndecan-1 


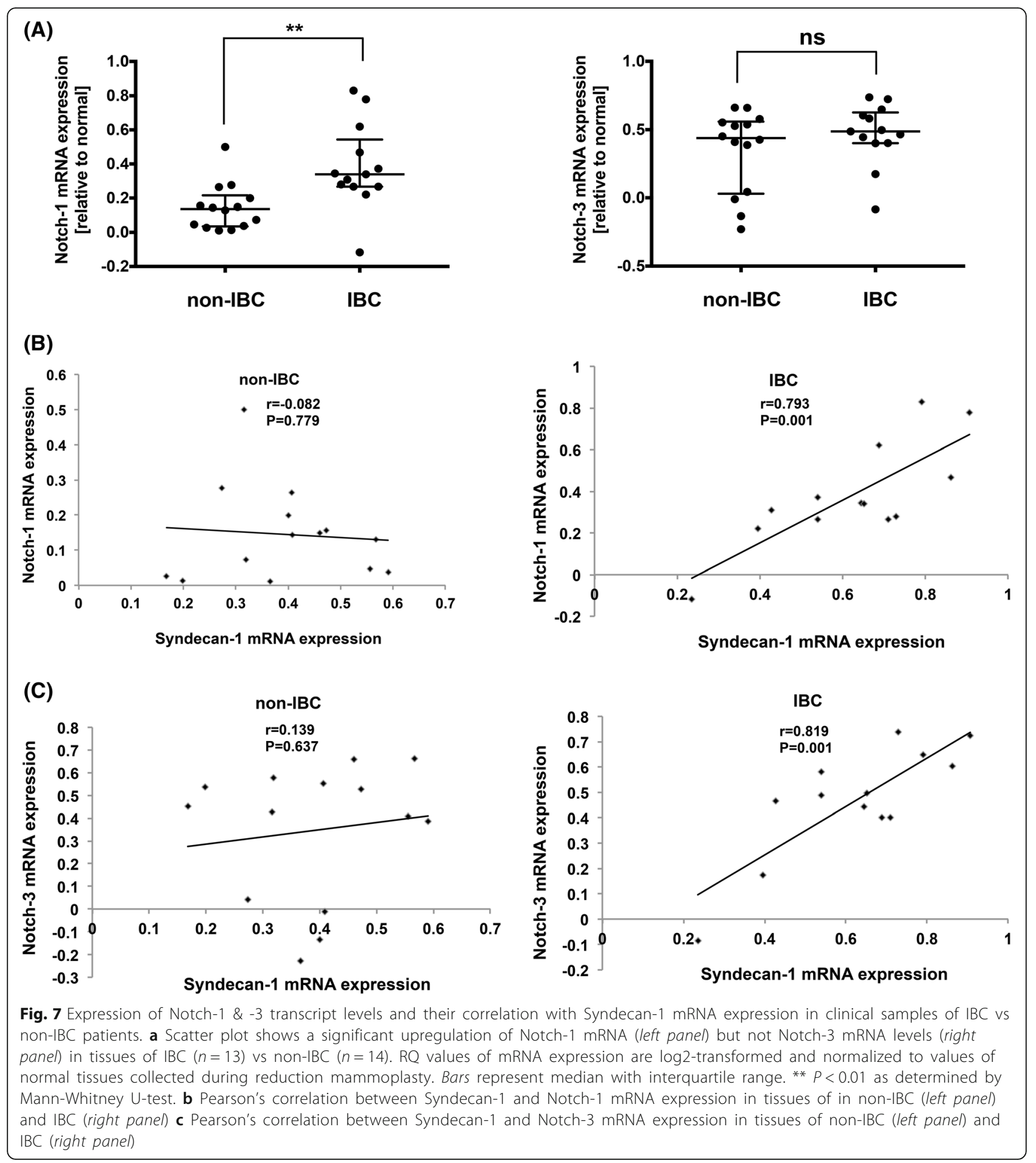

silencing has a functionally similar effect of Notch inhibition, we tested the effect of $1 \mu \mathrm{M}$ GSI on colony formation. Our data indicate that treatment with GSI abrogated completely colony formation in control and Syndecan-1 siRNA transfected SUM-149 cells (Data not shown).
Syndecan-1 regulates EGFR expression via Notch signaling and promotes EGF-induced colony formation in IBC

EGFR plays an essential role in IBC progression [31] and is correlated with Syndecan-1 expression in some tumor entities [36, 52]. However, the correlation between Syndecan-1 and EGFR in IBC is still unexplored. 
(A)
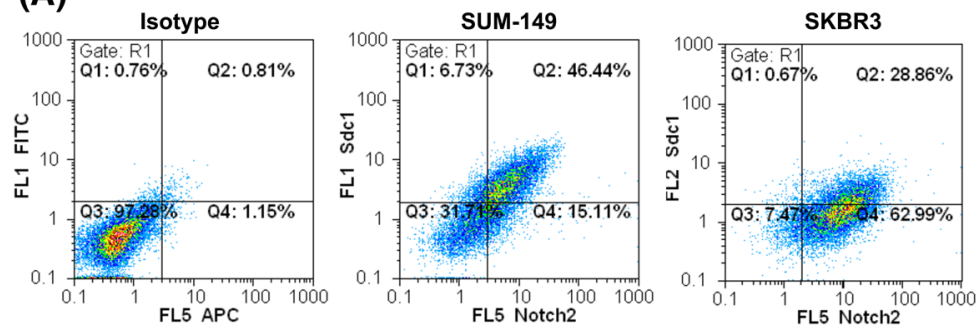

(B)

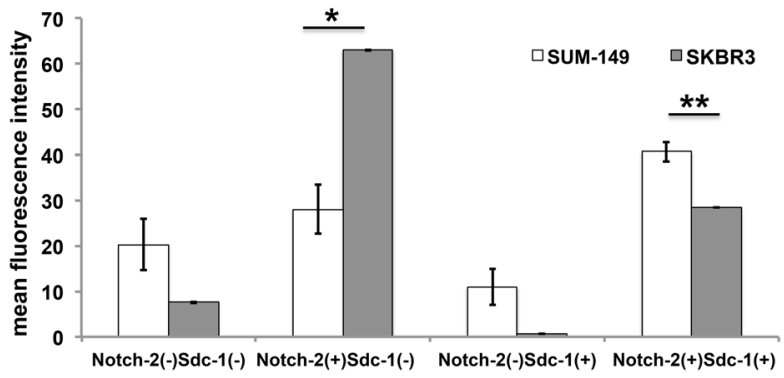

(C)
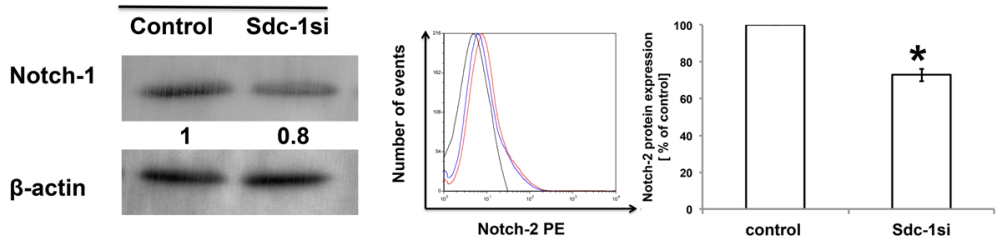

(D)

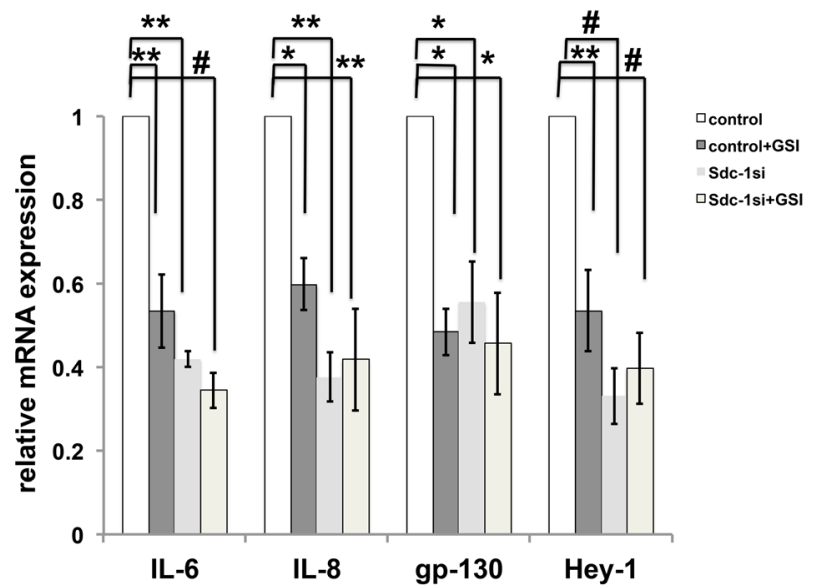

Fig. 8 Syndecan-1 regulates expression of Notch-1 \&-2 in SUM-149 cells. a A representative flow cytometric analysis for the expression of Syndecan-1 and Notch-2 in SUM-149 and SKBR-3. b Quantitative analysis of four subpopulations; Notch-2 $2^{(-)}$Syndecan- $1^{(-)}$, Notch- $2^{(+)}$Syndecan-1 ${ }^{(-)}$, Notch- $2^{(-)}$Syndecan- $1^{(+)}$and Notch- $2^{(+)}$Syndecan- $1^{(+)}$. Data represent mean \pm SEM, $n \geq 3 .{ }^{*} P<0.05,{ }^{*} P<0.01$ as determined by Student's t-test. $\mathbf{c}$ Syndecan-1 knockdown downregulates expression level of Notch-1 protein analyzed by Western blot (left panel) and Notch-2 protein analyzed by flow cytometry (right panel) in SUM-149 cells. Black line: unstained cells, red line: control cells, blue line: Syndecan-1 knockdown cells. * $P<0.05$ as determined by Student's t-test. Data shown are a single experiment representative of three independent experiments. d IL-6, IL-8, gp130 and Hey-1 mRNA levels post GSI treatment in SUM-149 cells. Data represent mean \pm SEM, $n \geq 3 .{ }^{*} P<0.05,{ }^{* *} P<0.01$ and ${ }^{\#} P<0.001$ as determined by one-way ANOVA followed by Tukey's multiple comparison test

Therefore, we sought to evaluate expression of EGFR mRNA and establish a correlation with Syndecan-1 mRNA in triple negative IBC vs non-IBC. Our qPCR data demonstrate EGFR mRNA was significantly higher expressed in tissues of IBC in comparison to those of non-IBC $(P<0.05) \quad$ (Fig. 9a). Interestingly, we found a 


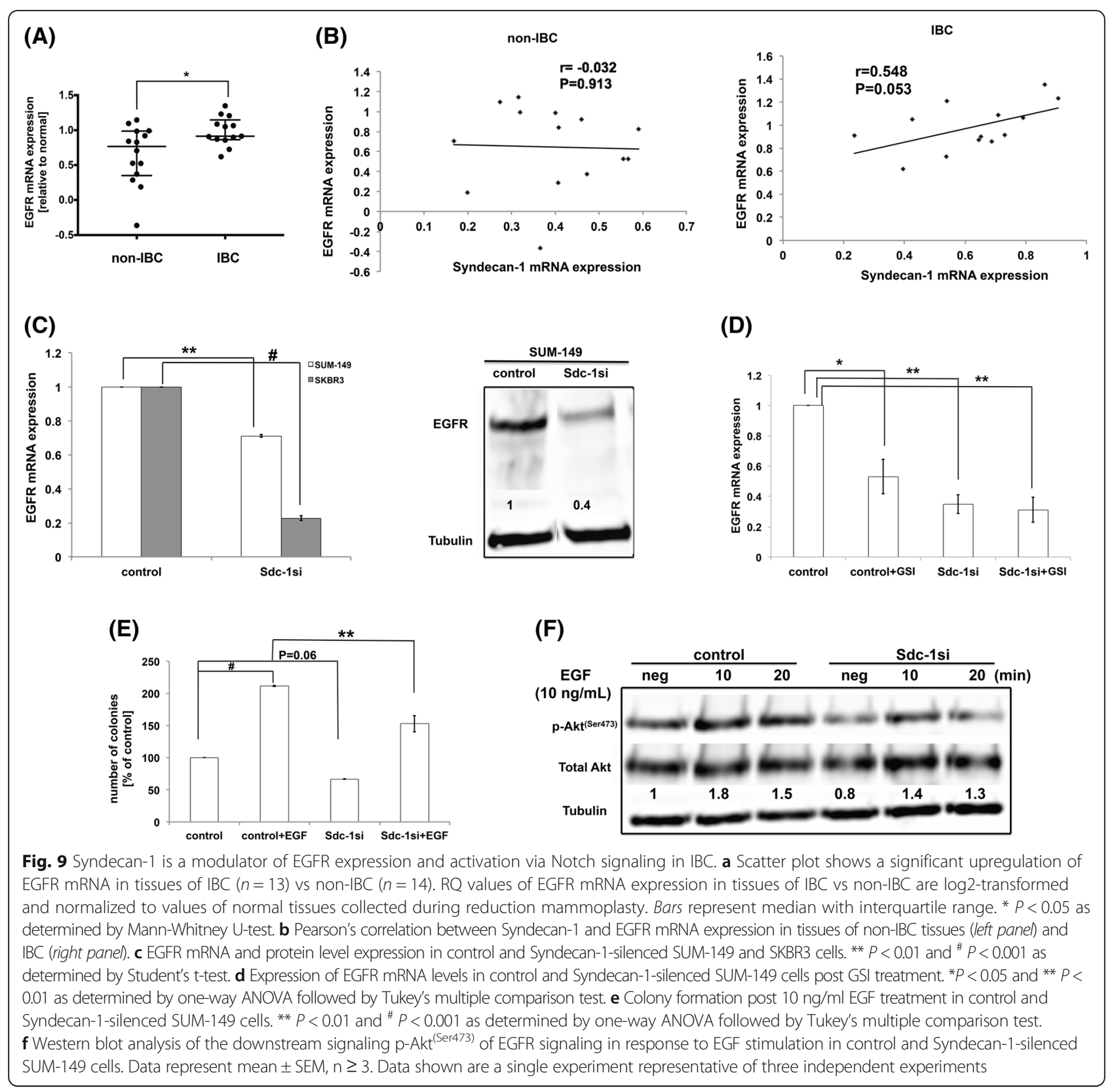

significant positive correlation between Syndecan-1 and EGFR mRNA expression in tissues of IBC $(r=0.548$, $P=0.05)$ (Fig. 9b), although this correlation was not observed in tissue of non-IBC $(r=-0.032, P=0.913)$ (Fig. 9b). These data prompted us to investigate the effect of Syndecan-1 depletion on EGFR expression in SUM-149 and SKBR3 cells. Our findings indicate that Syndecan-1 knockdown significantly reduced the mRNA expression level of EGFR by $29 \%$ in SUM-149 $(P<0.01)$ and by $77 \%$ in SKBR3 cells $(P<0.001)$ (Fig. 9c). Relative to control, we validated downregulation of EGFR protein expression by $60 \%$ upon Syndecan-1 knockdown in SUM-149 cells as determined by Western blot (Fig. 9c).
Since EGFR is known to be in a crosstalk with Notch signaling in different tumor entities including triple negative breast cancer $[53,54]$, we examined the effect of GSI on expression of EGFR transcript levels in control and Syndecan-1-depleted SUM-149 cells. Our qPCR data indicate a significant downregulation of EGFR mRNA level by $47 \%(P<0.05)$ in control cells upon Notch inhibitor treatment (Fig. 9d). Strikingly, treatment of Syndecan-1-silenced cells with Notch inhibitor did not further decrease EGFR expression, suggesting that EGFR expression is regulated by Syndecan-1 and Notch signaling. This finding was also substantiated at the functional level by treatment of control and 
Syndecan-1 knockdown SUM-149 cells with EGF to test its effect on colony formation. Syndecan-1 silencing significantly reduced colony formation in response to EGF by $58 \%(P<0.01)$ relative to EGFtreated control cells (Fig. 9e). Finally, we studied the effect of Syndecan-1 knockdown on the cell survival downstream target Akt of EGF/EGFR signaling in SUM-149 cells. As depicted in Fig. 9f, our Western blot data demonstrate Syndecan-1 silencing did not only downregulate basal level of the active form of Akt by $20 \%$ but also attenuated its activation status in response to EGF by $22 \%$ and $10 \%$ after 10 and 20 min stimulation compared to control SUM-149 cells, respectively.

\section{Discussion}

As Syndecan-1 is an important modulator of inflammation and the CSC phenotype in different experimental models and in cancer $[19,20]$, it emerges as a candidate marker for IBC. The current study demonstrates for the first time a higher transcript levels and immunohistochemical staining of Syndecan-1 in clinical samples of triple negative IBC vs non-IBC patients. This is consistent with the prognostic value of Syndecan-1 in different cancer entities, including breast cancer [55] and in line with the negative correlation between the ER, PR and the proportion of CD138-positive cells in ductal breast carcinoma in situ [23]. Interestingly, a higher expression of CD44 with a positive correlation with Syndecan-1 exists in tissues of IBC patients. Of note, Syndecan-1 expression is enriched in $\mathrm{CD}_{4} 4^{+}$subpopulation in SUM149 cells, although this enrichment is less in SKBR3 cells. This is in agreement with the notion of interaction between Syndecan-1 and CD44 promoting glioma cell invasion [56] and suggesting a physical and functional association as previously described $[57,58]$.

To extend our findings to in vitro models and to better understand its functional role, we studied the impact of Syndecan-1 silencing on CSC properties, namely ALDH1 activity and the presence and size of the $\mathrm{CD} 44^{(+)} \mathrm{CD} 24^{(-/ \text {low })}$ subpopulation, in SUM-149 cells. Our data revealed that Syndecan-1 silencing diminished the $\mathrm{CD} 44^{(+)} \mathrm{CD} 24^{(- \text {low })}$ and ALDH1-positive subsets compared with controls. These results are consistent with our previous data and other reports demonstrating that Syndecan-1 acts as a regulator of CSCs in triplenegative and ER-positive breast cancer [16, 29] and in prostate cancer [43]. These findings were confirmed in SKBR3 cells. ALDH1 positive cells were reduced upon Syndecan-1 silencing in this cell line. Taken together, these data provide evidence for a role of Syndecan-1 as a regulator of a CSC phenotype in different molecular subtypes of IBC and non-IBC cell lines.
One of the characteristic features of CSCs is the ability to form spheroids and colonies [16, 59]. Our in vitro colony and 3D spheroids formation assays revealed decreased numbers of spheroids formed in $3 \mathrm{D}$ and a reduction of colony numbers upon Syndecan-1 knockdown in SUM-149 and SKBR3 cells. This finding is supported by different reports: we have previously shown reduced mammosphere formation and impaired differentiation into cysts in Syndecan-1-depleted MCF-7 cells [16]. Another study showed that early intervention with a Syndecan-1 inhibitor (OGT2115) or RNAimediated Syndecan-1 silencing in a transgenic mouse model of prostate cancer reduced the incidence of adenocarcinoma and the number of $\mathrm{c}-\mathrm{kit}^{(+)} / \mathrm{CD} 44^{(+)}$cells in cancer foci [43].

It is well-known that breast CSCs are substantially regulated by a multitude of signaling pathways, including the IL-6/STAT3, Notch and Hedgehog pathways, and that targeting these pathways represents potential therapeutic approaches [28]. In this regard, we explored in this study the role of Syndecan-1 in regulating expression of components of the Notch signaling pathway. Interestingly, we found a higher expression of Notch-1 mRNA and a significant positive correlation between Notch-1 \& -3 and Syndecan-1 mRNA levels in carcinoma tissues of triple negative IBC vs non-IBC. Moreover, Syndecan-1 is expressed in a Notch- $2^{(+)}$-enriched subset with a prominent higher proportion in SUM-149 than that in SKBR3 cells. Additionally, our findings revealed that Syndecan-1 depletion led to downregulation of Notch-1, -3 and -4 , and the Notch signaling downstream target Hey-1 at the mRNA levels, and of Notch-1 \& -2 at the protein levels in SUM-149 cells. In contrast, only the mRNA level of Notch-3 was reduced in SKBR3 cells upon Syndecan-1 silencing. In support of our data, it was reported that the neural stem cells expressing both Syndecan-1 and Notch-1 have a higher capacity to form neurospheres than singly positive cells [60]. Another study demonstrated the presence of reciprocal regulation between Notch-2 \& -3 and Syndecan-2 in vascular muscle cells with a physical interaction between Syndecan-2 and Notch-3 [61]. Although Notch-2 has a dual role as a tumor suppressor or oncogene in breast cancer (reviewed in [62]), a recent study showed that treatment of patient-derived xenografts of epithelial tumors including breast with the Notch-2/Notch-3 antagonist tarextumab suppressed tumor growth and reduced tumor-initiating cell frequency [39]. In light of this finding, this is the first study reporting that Notch expression is influenced by Syndecan-1 in IBC.

IBC is known to secrete angiogenic and also vasculogenic growth factors, such as VEGF, bFGF, IL-6, and IL8 [63]. Coordinate expression and secretion of IL-6, IL-8 and $\mathrm{GRO}-\alpha$ via $\mathrm{NF}_{\kappa} \mathrm{B}$ promote tumorgenesis and are 
associated with poor outcome in triple negative breast cancer patients [51]. GRO chemokines are reported to enhance breast cancer metastasis and resistance to chemotherapy [64]. The maintenance of breast CSCs and their chemoresistance particularly in the basal subtype/triple negative breast cancer is essentially attributed to the synergistic effect between IL-6 $[27,65]$ and IL-8 $[66,67]$. Moreover, IL-6 promotes breast cancer bone metastasis through Notch-1 [68], and induces mammosphere formation in breast cancer cells through Notch-3 [65]. These data thus integrate the IL-6/STAT3 and Notch signaling pathways with relevance to our findings in IBC. SUM-149 cells secrete detectable levels of IL-6 and IL-8, and their expression enhances mammosphere formation and protects SUM-149 cells from radiation upon treatment with the Notch inhibitor RO4929097 [41]. We suggest that this effect can be dampened by Syndecan-1 downregulation. Indeed, treatment of SUM149 cells with Notch inhibitor reduced expression of IL6, IL-8 and gp130 mRNA levels to the same extent as Syndecan-1 knockdown without any additive effect of Notch inhibitor in Syndecan-1-depleted cells. Strikingly, the same effect was also observed for the direct downstream Notch target gene Hey-1, suggesting that Syndecan-1 and Notch signaling converge on the same downstream target. However, a potential caveat is associated with the interpretation of the gamma-secretase inhibitor study: Pasqualon et al. [69] have recently shown in a lung cancer model that the transmembrane fragment generated by Syndecan-1 shedding undergoes intramembrane proteolysis by gamma-secretase. If similar mechanisms apply to IBC cells, gamma-secretase inhibitor treatment may not only have directly affected the Notch signaling pathway, but also signaling events triggered by release of the cytoplasmic cleavage fragment of Syndecan-1 [70]. Overall, our data suggest the existence of a signaling axis involving Syndecan-1, Notch, IL-6/gp130 and IL-8 in IBC. Depletion of Syndecan-1 did not only downregulate expression of IL-6 and IL8 but also their secretion, thus inhibiting the positive autocrine feedback loop.

There is mounting evidence that the expression of inflammatory cytokines including IL- 6 is regulated by the transcription factors $\mathrm{NFKB}$ and STAT3 [71]. In fact, the NFkB transcription factor pathway contributes to the phenotype of IBC and its target genes are elevated in ER-versus ER+ breast tumors [72]. IL-6 is a direct regulator of breast CSC selfrenewal [65] and IL-6/JAK2/STAT3 pathway is more active in $\mathrm{CD} 44^{(+)} \mathrm{CD} 24^{(-/ \text {low })}$ breast cancer cells compared with other tumor cell types and its inhibition blocks the growth of xenografts [27]. A constitutively active STAT3 status is found in about $50-60 \%$ of breast tumors specifically in IBC after neoadjuvant chemotherapy [73], which is associated with tumorigenesis and drug resistance [74]. Moreover, STAT3 inhibition represses CSC traits in HER2-positive breast cancers [74]. In this context and in agreement with our prior observation in the triple negative MDA-MB-23 1 cells [16], Syndecan-1 knockdown reduced the levels of the activated forms of NFKB and/ or STAT3 and downregulated expression of the IL-6/ LIF coreceptor gp130 in SUM-149 and SKBR3 cells. Our findings in SKBR3 cells are supported by the observation of an increased IL-6 expression upon HER-2 overexpression, which leads to enhanced breast CSC activity and resistance against anti-HER2 treatment via a STAT3/Akt/NFkB signaling-mediated autocrinepositive feedback loop $[75,76]$. Taken together, this proves the efficacy of Syndecan-1 targeting in dampening the inflammatory signaling mediated by $\mathrm{NF \kappa B}$ or STAT3 in the two cellular models of different breast cancer subtypes.

An important cue for IBC pathogenesis and progression is EGFR [34]. Our data suggest presence of cross-talk between EGFR and Syndecan-1 in IBC. This is reflected by downregulation of EGFR mRNA and protein levels in SUM-149 and the positive correlation in the clinical samples of IBC. Interestingly, we demonstrated that Notch inhibition did not further downregulate expression of EGFR in Syndecan-1silenced cells, suggesting that Syndecan-1 regulates expression of EGFR via Notch signaling. This is in agreement with the notion of the crosstalk of EGFR with Notch signaling in triple negative breast cancer and their dual inhibition drastically attenuated active $\left.\mathrm{Akt}^{(\mathrm{Ser} 473}\right)$ [53, 77]. Given the coreceptor function of Syndecan-1 for growth factors [18] and downregulation of EGFR expression upon Syndecan-1 silencing, we found downregulation of the EGFR downstream signaling cue pAkt ${ }^{\text {(Ser473 })}$ upon treatment with EGF in Syndecan-1 knockdown cells compared to control SUM-149 cells. At the functional level, Syndecan-1 silencing reduced EGF-induced colony formation compared to control SUM-149 cells. Taken together, our results suggest that Syndecan-1 further regulates a CSC phenotype via EGFR expression and implies a role of interconnected Syndecan-1, Notch and EGFR signaling in IBC.

\section{Conclusions}

In conclusion, this study identifies Syndecan-1 as a novel molecular marker in IBC patients and future studies on larger patient collectives will help to define the full prognostic and predictive value of Syndecan-1 in IBC. Additionally, our data provide evidence for the role played by Syndecan-1 in synchronously fine tuning multiple signaling pathways including IL-6/STAT3/gp130, 


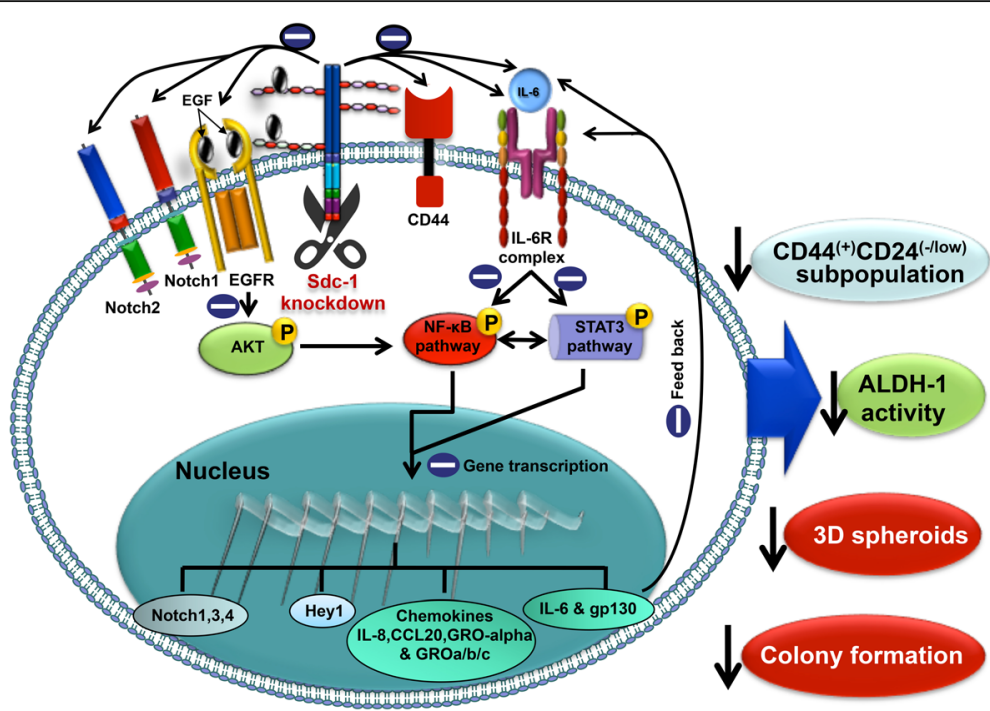

Fig. 10 Summary of the mode of action exerted by Syndecan-1 in IBC progression. Syndecan-1 modulates expression and activation of the components of multiple signaling pathways including Notch, EGF/EGFR, and IL-6/STAT3/gp130. These changes have an impact on several features of the breast CSC phenotype, including CSC marker expression, and the formation of colonies and 3D spheroids

inflammatory cytokines, Notch, and EGFR, implicated in breast cancer stemness (Fig. 10). Therefore, this study underscores the translational relevance of Syndecan-1 targeting to dampen multiple and intersected signaling pathways-induced CSC phenotype in triple negative IBC patients.

\section{Additional files}

Additional file 1: Table S1. Primers sequences. (DOCX $18 \mathrm{~kb}$ )

Additional file 2: Figure S1. A representative image of tumor emboli, a unique feature for tissues of IBC patients showing a positive staining for CD44 and Syndecan-1. (ZIP 2337 kb)

Additional file 3: Figure S2. Flow cytometric analysis of Syndecan-1 expression in control and Syndecan-1 siRNA transfected SUM-149 cells. 500,000 cells were stained for isotype control mouse lgG1-PE and mouse anti-human Syndecan-1 (CD138)-PE and the cells were subjected to flow cytometry. Each plot shows mouse lgG-PE control (dotted line) and CD138PE-stained cells (solid line). The median fluorescence intensity (MFI) of events is given for each peak. Data are a single experiment representative of three independent experiments. (ZIP $281 \mathrm{~kb}$ )

\section{Abbreviations}

ALDH-1: Aldehyde dehydrogenase-1; ANOVA: Analysis of variance; CSC: Cancer stem cell; DEAB: Diethylaminobenzaldehyde; EGFR: Epidermal growth factor receptor; ER/PR: Estrogen receptor/Progesterone receptor; FCS: Fetal calf serum; GSI: Gamma secretase inhibitor; HER-2: Human epidermal growth factor receptor; IBC: Inflammatory breast cancer; NFkB: Nuclear factor kappa B; qPCR: Quantitative real time polymerase chain reaction; Sdc-1: Syndecan-1; siRNA: Small interfering ribonucleic acid; STAT3: Signal transducer and activator of transcription 3

\section{Acknowledgements}

The authors would like to thank Prof. Dr. Mohamed Akram Nouh (National Cancer Institute, Cairo University, Egypt) for his help in reading immunohistochemical-staining results, and Birgit Pers and Angelika van Dülmen for technical assistance. Special thanks for Ms. Noura El-Husseiny for her kind assistance in Notch inhibition experiments.

\section{Funding}

This work was supported by Science and Technology Development Funds (STDF), Egypt, Reintegration project ID\#6309 (to SAl, HH, ME and MMM), German Academic Exchange Service (DAAD) \#56808461 Al Tawasul (to SAl and MG), EU H2020 MSCA-RISE GLYCANC \#645756 (to SAl, MMM and MG), Cairo University Scientific Research Sector (to SAI, HH and MMM) and Avon Foundation-USA (to MMM). We acknowledge support by Open Access Publication Fund of University of Muenster.

\section{Availability of data and materials}

Not applicable.

\section{Authors' contributions}

$\mathrm{SAI}, \mathrm{HH}, \mathrm{BG}, \mathrm{MMM}$ and $\mathrm{MG}$ conceived and designed experiments. SAI, RG, EAE, OS, HTM, HH, BG conducted experiments. ME was responsible for patients' recruitment. SAI, RG, EAE, OS, HTM, HH, ME analyzed data. SAI, HH, BG, ME, $M M M$ and $M G$ edited and/or drafted the manuscript. SAl supervised the study. All authors have read and approved the final version of the manuscript.

\section{Competing interests}

The authors declare that they have no competing interests.

\section{Consent for publication}

Not applicable.

Ethics approval and consent to participate

We obtained Institutional Review Board (IRB\#00006379) approval from research ethics committee of General Surgery Department, Faculty of medicine, Ain Shams University, Cairo, Egypt. All patients enrolled in this study signed written informed consent to participate in this study.

\section{Author details}

'Department of Zoology, Faculty of Science, Cairo University, 12613 Giza, Egypt. ${ }^{2}$ Department of Radiotherapy-Radiooncology, University Hospital Münster, Münster, Germany. ${ }^{3}$ Department of General Surgery, Faculty of Medicine, Ain Shams University, 11566 Cairo, Egypt. ${ }^{4}$ Department of Gynecology and Obstetrics, Münster University Hospital, Albert-Schweitzer-Campus 1, D11, 48149 Münster, Germany. 
Received: 11 July 2016 Accepted: 22 February 2017

Published online: 07 March 2017

\section{References}

1. Hance KW, Anderson WF, Devesa SS, Young HA, Levine PH. Trends in inflammatory breast carcinoma incidence and survival: the surveillance, epidemiology, and end results program at the National Cancer Institute. J Natl Cancer Inst. 2005;97(13):966-75.

2. Soliman AS, Banerjee M, Lo AC, Ismail K, Hablas A, Seifeldin IA, Ramadan M, Omar HG, Fokuda A, Harford JB, et al. High proportion of inflammatory breast cancer in the Population-based Cancer Registry of Gharbiah, Egypt Breast J. 2009;15(4):432-4.

3. Boussen H, Bouzaiene H, Ben Hassouna J, Gamoudi A, Benna F, Rahal K Inflammatory breast cancer in Tunisia: reassessment of incidence and clinicopathological features. Semin Oncol. 2008;35(1):17-24

4. Robertson FM, Bondy M, Yang W, Yamauchi H, Wiggins S, Kamrudin S, Krishnamurthy S, Le-Petross $\mathrm{H}$, Bidaut L, Player AN, et al. Inflammatory breast cancer: the disease, the biology, the treatment. CA Cancer J Clin. 2010;60(6):351-75.

5. Cristofanilli M, Valero V, Buzdar AU, Kau SW, Broglio KR, Gonzalez-Angulo AM, Sneige N, Islam R, Ueno NT, Buchholz TA, et al. Inflammatory breast cancer (IBC) and patterns of recurrence: understanding the biology of a unique disease. Cancer. 2007;110(7):1436-44.

6. Singletary SE, Cristofanilli M. Defining the clinical diagnosis of inflammatory breast cancer. Semin Oncol. 2008;35(1):7-10.

7. Li J, Gonzalez-Angulo AM, Allen PK, Yu TK, Woodward WA, Ueno NT, Lucci A, Krishnamurthy S, Gong Y, Bondy ML, et al. Triple-negative subtype predicts poor overall survival and high locoregional relapse in inflammatory breast cancer. Oncologist. 2011;16(12):1675-83.

8. Nielsen TO, Hsu FD, Jensen K, Cheang M, Karaca G, Hu Z, HernandezBoussard T, Livasy C, Cowan D, Dressler L, et al. Immunohistochemical and clinical characterization of the basal-like subtype of invasive breast carcinoma. Clin Cancer Res. 2004;10(16):5367-74.

9. Bertucci F, Finetti P, Rougemont J, Charafe-Jauffret E, Nasser V, Loriod B, Camerlo J, Tagett R, Tarpin C, Houvenaeghel G, et al. Gene expression profiling for molecular characterization of inflammatory breast cancer and prediction of response to chemotherapy. Cancer Res. 2004:64(23):8558-65.

10. Van Laere SJ, Van den Eynden GG, Van der Auwera I, Vandenberghe M, van Dam P, Van Marck EA, van Golen KL, Vermeulen PB, Dirix LY. Identification of cell-of-origin breast tumor subtypes in inflammatory breast cancer by gene expression profiling. Breast Cancer Res Treat. 2006;95(3):243-55.

11. Chaher N, Arias-Pulido H, Terki N, Qualls C, Bouzid K, Verschraegen C, Wallace AM, Royce M. Molecular and epidemiological characteristics of inflammatory breast cancer in Algerian patients. Breast Cancer Res Treat 2012;131(2):437-44.

12. Dawood S, Ueno NT, Valero V, Woodward WA, Buchholz TA, Hortobagyi GN, Gonzalez-Angulo AM, Cristofanilli M. Differences in survival among women with stage III inflammatory and noninflammatory locally advanced breast cancer appear early: a large population-based study. Cancer. 2011;117(9):1819-26.

13. Charafe-Jauffret E, Ginestier C, lovino F, Tarpin C, Diebel M, Esterni B, Houvenaeghel G, Extra JM, Bertucci F, Jacquemier J, et al. Aldehyde dehydrogenase 1-positive cancer stem cells mediate metastasis and poor clinical outcome in inflammatory breast cancer. Clin Cancer Res. 2010;16(1):45-55.

14. Pardal R, Clarke MF, Morrison SJ. Applying the principles of stem-cell biology to cancer. Nat Rev Cancer. 2003;3(12):895-902.

15. Gotte M. Endometrial cells get side-tracked: side population cells promote epithelial-mesenchymal transition in endometrial carcinoma. Am J Pathol. 2010;176(1):25-8

16. Ibrahim SA, Hassan H, Vilardo L, Kumar SK, Kumar AV, Kelsch R, Schneider C, Kiesel L, Eich HT, Zucchi I, et al. Syndecan-1 (CD138) modulates triplenegative breast cancer stem cell properties via regulation of LRP-6 and IL-6mediated STAT3 signaling. PLoS One. 2013;8(12):e85737.

17. Bernfield M, Gotte M, Park PW, Reizes O, Fitzgerald ML, Lincecum J, Zako M. Functions of cell surface heparan sulfate proteoglycans. Annu Rev Biochem. 1999;68:729-77.

18. Nikolova V, Koo CY, Ibrahim SA, Wang Z, Spillmann D, Dreier R, Kelsch R, Fischgrabe J, Smollich M, Rossi LH, et al. Differential roles for membranebound and soluble syndecan-1 (CD138) in breast cancer progression. Carcinogenesis. 2009;30(3):397-407

19. Hassan H, Greve B, Pavao MS, Kiesel L, Ibrahim SA, Gotte M. Syndecan-1 modulates beta-integrin-dependent and interleukin-6-dependent functions in breast cancer cell adhesion, migration, and resistance to irradiation. FEBS J. 2013;280(10):2216-27.

20. Gotte M, Echtermeyer F. Syndecan-1 as a regulator of chemokine function. ScientificWorldJournal. 2003:3:1327-31.

21. Barbouri D, Afratis N, Gialeli C, Vynios DH, Theocharis AD, Karamanos NK. Syndecans as modulators and potential pharmacological targets in cancer progression. Front Oncol. 2014;4:4.

22. Ibrahim SA, Yip GW, Stock C, Pan JW, Neubauer C, Poeter M, Pupjalis D, Koo CY, Kelsch R, Schule R, et al. Targeting of syndecan-1 by microRNA miR-10b promotes breast cancer cell motility and invasiveness via a Rho-GTPaseand E-cadherin-dependent mechanism. Int J Cancer. 2012;131(6):E884-96.

23. Tiemann K, Weigel MT, Alkatout I, Wenners AS, Mundhenke H, Schafer FW, Bauer M, Schem C, Maass N, Jonat W, et al. Significance of syndecan-1 expression in ductal carcinoma in situ of the breast. Anticancer Res. 2014;34(7):3607-16.

24. Leivonen M, Lundin J, Nordling S, von Boguslawski K, Haglund C. Prognostic value of syndecan-1 expression in breast cancer. Oncology. 2004;67(1):11-8.

25. Loussouarn D, Campion L, Sagan C, Frenel JS, Dravet F, Classe JM, PioudMartigny R, Berton-Rigaud D, Bourbouloux E, Mosnier JF, et al. Prognostic impact of syndecan-1 expression in invasive ductal breast carcinomas. $\mathrm{Br}$ Cancer. 2008;98(12):1993-8.

26. Gotte M, Kersting C, Radke I, Kiesel L, Wulfing P. An expression signature of syndecan-1 (CD138), E-cadherin and c-met is associated with factors of angiogenesis and lymphangiogenesis in ductal breast carcinoma in situ. Breast Cancer Res. 2007;9(1):R8

27. Marotta LL, Almendro V, Marusyk A, Shipitsin M, Schemme J, Walker SR, Bloushtain-Qimron N, Kim JJ, Choudhury SA, Maruyama R, et al. The JAK2/ STAT3 signaling pathway is required for growth of CD44(+)CD24(-) stem celllike breast cancer cells in human tumors. J Clin Invest. 2011;121(7):2723-35.

28. Takebe N, Miele L, Harris PJ, Jeong W, Bando H, Kahn M, Yang SX, Ivy SP. Targeting Notch, Hedgehog, and Wnt pathways in cancer stem cells: clinical update. Nat Rev Clin Oncol. 2015;12(8):445-64.

29. Alexander CM, Reichsman F, Hinkes MT, Lincecum J, Becker KA, Cumberledge S, Bernfield M. Syndecan-1 is required for Wnt-1-induced mammary tumorigenesis in mice. Nat Genet. 2000;25(3):329-32.

30. McDermott SP, Ranheim EA, Leatherberry VS, Khwaja SS, Klos KS, Alexander CM. Juvenile syndecan-1 null mice are protected from carcinogen-induced tumor development. Oncogene. 2007;26(10):1407-16.

31. Cabioglu N, Gong Y, Islam R, Broglio KR, Sneige N, Sahin A, GonzalezAngulo AM, Morandi P, Bucana C, Hortobagyi GN, et al. Expression of growth factor and chemokine receptors: new insights in the biology of inflammatory breast cancer. Ann Oncol. 2007;18(6):1021-9.

32. Suarez-Arroyo IJ, Rios-Fuller TJ, Feliz-Mosquea YR, Lacourt-Ventura M, LealAlviarez DJ, Maldonado-Martinez G, Cubano LA, Martinez-Montemayor MM. Ganoderma lucidum Combined with the EGFR Tyrosine Kinase Inhibitor, Erlotinib Synergize to Reduce Inflammatory Breast Cancer Progression. J Cancer. 2016;7(5):500-11.

33. Yamauchi $\mathrm{H}$, Ueno NT. Targeted therapy in inflammatory breast cancer. Cancer. 2010;116(11 Suppl):2758-9.

34. Van Laere SJ, Van der Auwera I, Van den Eynden GG, van Dam P, Van Marck EA, Vermeulen PB, Dirix LY. NF-kappaB activation in inflammatory breast cancer is associated with oestrogen receptor downregulation, secondary to EGFR and/or ErbB2 overexpression and MAPK hyperactivation. Br J Cancer. 2007:97(5):659-69.

35. Zheng Z, Shao N, Weng H, Li W, Zhang J, Zhang L, Yang L, Ye S. Correlation between epidermal growth factor receptor and tumor stem cell markers CD44/CD24 and their relationship with prognosis in breast invasive ductal carcinoma. Med Oncol. 2015;32(1):275.

36. Kim SY, Choi EJ, Yun JA, Jung ES, Oh ST, Kim JG, Kang WK, Lee SH. Syndecan-1 expression is associated with tumor size and EGFR expression in colorectal carcinoma: a clinicopathological study of 230 cases. Int J Med Sci. 2015;12(2):92-9.

37. An H, Kim JY, Oh E, Lee N, Cho Y, Seo JH. Salinomycin Promotes Anoikis and Decreases the CD44+/CD24- Stem-Like Population via Inhibition of STAT3 Activation in MDA-MB-231 Cells. PLoS One. 2015;10(11):e0141919.

38. van der Zee M, Sacchetti A, Cansoy M, Joosten R, Teeuwssen M, HeijmansAntonissen C, Ewing-Graham PC, Burger CW, Blok LJ, Fodde R. IL6/JAK1/ STAT3 Signaling Blockade in Endometrial Cancer Affects the ALDHhi/CD126 + Stem-like Component and Reduces Tumor Burden. Cancer Res. 2015: 75(17):3608-22.

39. Yen WC, Fischer MM, Axelrod F, Bond C, Cain J, Cancilla B, Henner WR, Meisner R, Sato A, Shah J, et al. Targeting Notch signaling with a Notch2/ 
Notch3 antagonist (tarextumab) inhibits tumor growth and decreases tumor-initiating cell frequency. Clin Cancer Res. 2015;21(9):2084-95.

40. Elghonaimy EA, Ibrahim SA, Youns A, Hussein Z, Nouh MA, El-Mamlouk T, El-Shinawi M, Mostafa Mohamed M. Secretome of tumor-associated leukocytes augment epithelial-mesenchymal transition in positive lymph node breast cancer patients via activation of EGFR/Tyr845 and NF-kappaB/ p65 signaling pathway. Tumour Biol. 2016;37(9):12441-53.

41. Debeb BG, Cohen EN, Boley K, Freiter EM, Li L, Robertson FM, Reuben JM, Cristofanilli M, Buchholz TA, Woodward WA. Pre-clinical studies of Notch signaling inhibitor RO4929097 in inflammatory breast cancer cells. Breast Cancer Res Treat. 2012;134(2):495-510.

42. Mazurek A, Luo W, Krasnitz A, Hicks J, Powers RS, Stillman B. DDX5 regulates DNA replication and is required for cell proliferation in a subset of breast cancer cells. Cancer Discov. 2012;2(9):812-25.

43. Shimada K, Anai S, Fujii T, Tanaka N, Fujimoto K, Konishi N. Syndecan-1 (CD138) contributes to prostate cancer progression by stabilizing tumourinitiating cells. J Pathol. 2013;231(4):495-504.

44. Xiao Y, Ye Y, Yearsley K, Jones S, Barsky SH. The lymphovascular embolus of inflammatory breast cancer expresses a stem cell-like phenotype. Am J Pathol. 2008;173(2):561-74.

45. Hui CC, Angers S. Gli proteins in development and disease. Annu Rev Cell Dev Biol. 2011;27:513-37.

46. Blotta S, Jakubikova J, Calimeri T, Roccaro AM, Amodio N, Azab AK, Foresta U, Mitsiades CS, Rossi M, Todoerti K, et al. Canonical and noncanonical Hedgehog pathway in the pathogenesis of multiple myeloma. Blood. 2012; 120(25):5002-13

47. Boyle ST, Faulkner JW, McColl SR, Kochetkova M. The chemokine receptor CCR6 facilitates the onset of mammary neoplasia in the MMTV-PyMT mouse model via recruitment of tumor-promoting macrophages. Mol Cancer. 2015;14:115.

48. Alaaeddine N, Hilal G, Baddoura R, Antoniou J, Di Battista JA. CCL20 stimulates proinflammatory mediator synthesis in human fibroblast-like synoviocytes through a MAP kinase-dependent process with transcriptional and posttranscriptional control. J Rheumatol. 2011;38(9):1858-65.

49. Kharabi Masouleh B, Ten Dam GB, Wild MK, Seelige R, van der Vlag J, Rops $A L$, Echtermeyer FG, Vestweber D, van Kuppevelt TH, Kiesel $L$, et al. Role of the heparan sulfate proteoglycan syndecan-1 (CD138) in delayed-type hypersensitivity. J Immunol. 2009;182(8):4985-93.

50. Baston-Bust DM, Gotte M, Janni W, Krussel JS, Hess AP. Syndecan-1 knockdown in decidualized human endometrial stromal cells leads to significant changes in cytokine and angiogenic factor expression patterns. Reprod Biol Endocrinol. 2010;8:133

51. Hartman ZC, Poage GM, den Hollander P, Tsimelzon A, Hill J, Panupinthu N, Zhang Y, Mazumdar A, Hilsenbeck SG, Mills GB, et al. Growth of triple-negative breast cancer cells relies upon coordinate autocrine expression of the proinflammatory cytokines IL-6 and IL-8. Cancer Res. 2013;73(11):3470-80.

52. Wang X, Zuo D, Chen Y, Li W, Liu R, He Y, Ren L, Zhou L, Deng T, Wang $X$, et al. Shed Syndecan-1 is involved in chemotherapy resistance via the EGFR pathway in colorectal cancer. Br J Cancer. 2014;111(10): 1965-76.

53. Dai J, Ma D, Zang S, Guo D, Qu X, Ye J, Ji C. Cross-talk between Notch and EGFR signaling in human breast cancer cells. Cancer Invest. 2009;27(5):533-40.

54. Giannopoulou E, Nikolakopoulos A, Kotsirilou D, Lampropoulou A, Raftopoulou S, Papadimitriou E, Theocharis AD, Makatsoris T, Fasseas K, Kalofonos HP. Epidermal growth factor receptor status and Notch inhibition in non-small cell lung cancer cells. J Biomed Sci. 2015;22:98.

55. Barbareschi M, Maisonneuve P, Aldovini D, Cangi MG, Pecciarini L, Angelo Mauri F, Veronese S, Caffo O, Lucenti A, Palma PD, et al. High syndecan-1 expression in breast carcinoma is related to an aggressive phenotype and to poorer prognosis. Cancer. 2003;98(3):474-83.

56. Jiang YX, Ma Y, Cheng Y. Transcriptome and coexpression network analysis of the human glioma cell line Hs683 exposed to candoxin. J Int Med Res. 2012;40(3):887-98.

57. Ricciardelli C, Rodgers RJ. Extracellular matrix of ovarian tumors. Semin Reprod Med. 2006;24(4):270-82.

58. Suhovskih AV, Aidagulova SV, Kashuba VI, Grigorieva EV. Proteoglycans as potential microenvironmental biomarkers for colon cancer. Cell Tissue Res. 2015;361(3):833-44.

59. Ponti D, Costa A, Zaffaroni N, Pratesi G, Petrangolini G, Coradini D, Pilotti S, Pierotti MA, Daidone MG. Isolation and in vitro propagation of tumorigenic breast cancer cells with stem/progenitor cell properties. Cancer Res. 2005; 65(13):5506-11.
60. Nagato M, Heike T, Kato T, Yamanaka Y, Yoshimoto M, Shimazaki T, Okano $\mathrm{H}$, Nakahata T. Prospective characterization of neural stem cells by flow cytometry analysis using a combination of surface markers. J Neurosci Res. 2005:80(4):456-66.

61. Zhao N, Liu H, Lilly B. Reciprocal regulation of syndecan-2 and Notch signaling in vascular smooth muscle cells. J Biol Chem. 2012;287(20):16111-20.

62. Han J, Hendzel MJ, Allalunis-Turner J. Notch signaling as a therapeutic target for breast cancer treatment? Breast Cancer Res. 2011;13(3):210.

63. van Golen KL, Wu ZF, Qiao XT, Bao L, Merajver SD. RhoC GTPase overexpression modulates induction of angiogenic factors in breast cells. Neoplasia. 2000;2(5):418-25.

64. Acharyya S, Oskarsson T, Vanharanta S, Malladi S, Kim J, Morris PG, ManovaTodorova K, Leversha M, Hogg N, Seshan VE, et al. A CXCL1 paracrine network links cancer chemoresistance and metastasis. Cell. 2012;150(1):165-78.

65. Sansone P, Storci G, Tavolari S, Guarnieri T, Giovannini C, Taffurelli M, Ceccarelli C, Santini D, Paterini P, Marcu KB, et al. IL-6 triggers malignant features in mammospheres from human ductal breast carcinoma and normal mammary gland. J Clin Invest. 2007;117(12):3988-4002.

66. Bhola NE, Balko JM, Dugger TC, Kuba MG, Sanchez V, Sanders M, Stanford J, Cook RS, Arteaga CL. TGF-beta inhibition enhances chemotherapy action against triple-negative breast cancer. J Clin Invest. 2013;123(3):1348-58.

67. Ginestier C, Liu S, Diebel ME, Korkaya H, Luo M, Brown M, Wicinski J, Cabaud O, Charafe-Jauffret E, Birnbaum D, et al. CXCR1 blockade selectively targets human breast cancer stem cells in vitro and in xenografts. J Clin Invest. 2010;120(2):485-97.

68. Sethi N, Dai X, Winter CG, Kang Y. Tumor-derived JAGGED1 promotes osteolytic bone metastasis of breast cancer by engaging notch signaling in bone cells. Cancer Cell. 2011;19(2):192-205.

69. Pasqualon T, Pruessmeyer J, Weidenfeld S, Babendreyer A, Groth E, Schumacher J, Schwarz N, Denecke B, Jahr H, Zimmermann P, et al. A transmembrane C-terminal fragment of syndecan-1 is generated by the metalloproteinase ADAM17 and promotes lung epithelial tumor cell migration and lung metastasis formation. Cell Mol Life Sci. 2015;72(19):3783-801.

70. Pasqualon T, Pruessmeyer J, Jankowski V, Babendreyer A, Groth $E$, Schumacher J, Koenen A, Weidenfeld S, Schwarz N, Denecke B, et al. A cytoplasmic C-terminal fragment of Syndecan-1 is generated by sequential proteolysis and antagonizes Syndecan-1 dependent lung tumor cell migration. Oncotarget. 2015;6(31):31295-312.

71. Grivennikov SI, Karin M. Dangerous liaisons: STAT3 and NF-kappaB collaboration and crosstalk in cancer. Cytokine Growth Factor Rev. 2010;21(1):11-9.

72. Van Laere SJ, Van der Auwera I, Van den Eynden GG, Elst HJ, Weyler J, Harris $A L$, van Dam P, Van Marck EA, Vermeulen PB, Dirix LY. Nuclear factor-kappaB signature of inflammatory breast cancer by CDNA microarray validated by quantitative real-time reverse transcription-PCR, immunohistochemistry, and nuclear factor-kappaB DNA-binding. Clin Cancer Res. 2006;12(11 Pt 1):3249-56.

73. Jhaveri K, Teplinsky E, Silvera D, Valeta-Magara A, Arju R, Giashuddin S, Sarfraz Y, Alexander M, Darvishian F, Levine PH, et al. Hyperactivated mTOR and JAK2/STAT3 Pathways: Molecular Drivers and Potential Therapeutic Targets of Inflammatory and Invasive Ductal Breast Cancers After Neoadjuvant Chemotherapy. Clin Breast Cancer. 2016;16(2):113-22.e1.

74. Chung SS, Giehl N, Wu Y, Vadgama JV. STAT3 activation in HER2overexpressing breast cancer promotes epithelial-mesenchymal transition and cancer stem cell traits. Int J Oncol. 2014;44(2):403-11.

75. Korkaya H, Kim Gl, Davis A, Malik F, Henry NL, Ithimakin S, Quraishi AA, Tawakkol N, D'Angelo R, Paulson AK, et al. Activation of an IL6 inflammatory loop mediates trastuzumab resistance in HER2+ breast cancer by expanding the cancer stem cell population. Mol Cell. 2012:47(4):570-84.

76. Hartman ZC, Yang XY, Glass O, Lei G, Osada T, Dave SS, Morse MA, Clay TM, Lyerly HK HER2 overexpression elicits a proinflammatory IL-6 autocrine signaling loop that is critical for tumorigenesis. Cancer Res. 2011;71(13):4380-91.

77. Meurette O, Stylianou S, Rock R, Collu GM, Gilmore AP, Brennan K. Notch activation induces Akt signaling via an autocrine loop to prevent apoptosis in breast epithelial cells. Cancer Res. 2009;69(12):5015-22. 